ANL-7420

Engineering and

Equipment (TID -4500)

AEC Research and

Development Report

ARGONNE NATIONAL LABORATORY

9700 South Cass Avenue

Argonne, Illinois 60439

\title{
TRANSIENT THERMAL STRESSES \\ ASSOCIATED WITH SUDDEN INITIATION \\ OF INTERNAL HEAT GENERATION IN A \\ SEGMENT OF A CIRCULAR CYLINDER
}

by

Richard A. Valentin

and Daniel F. Schoeberle*

Reactor Engineering Division

\section{LEGAL NOTICE}

This report was prepared as an account of Government sponsored work. Neither the United States, nor the Commission, nor any person acting on behalf of the Commission:

A. Makes any warranty or representation, expressed or implied, with respect to the accuracy, completeness, or usefulness of the information contsined in this report, or that the use of any information, apparatus, method, or process disclosed in this report may not infringe privately owned rights, or

B. Assumes any liabilities with respect to the use of, or for damages resulting from the use of any information, apparatus, method, or process disclosed in this report.

As used in the above, "person acting on behalf of the Commlssion" includes any employee or contractor of the Commission, or employee of such contractor, to the extent that such employee or contractor of the Commission, or employee of such contractor prepares, disseminates, or provides access to, any information pursuant to his employment or contract with the Commission, or his employment with such contractor.

March 1968

*Department of Materials Engineering, University of Illinois - Chicago Circle. 


\section{DISCLAIMER}

This report was prepared as an account of work sponsored by an agency of the United States Government. Neither the United States Government nor any agency Thereof, nor any of their employees, makes any warranty, express or implied, or assumes any legal liability or responsibility for the accuracy, completeness, or usefulness of any information, apparatus, product, or process disclosed, or represents that its use would not infringe privately owned rights. Reference herein to any specific commercial product, process, or service by trade name, trademark, manufacturer, or otherwise does not necessarily constitute or imply its endorsement, recommendation, or favoring by the United States Government or any agency thereof. The views and opinions of authors expressed herein do not necessarily state or reflect those of the United States Government or any agency thereof. 


\section{DISCLAIMER}

Portions of this document may be illegible in electronic image products. Images are produced from the best available original document. 
TABLE OF CONTENTS

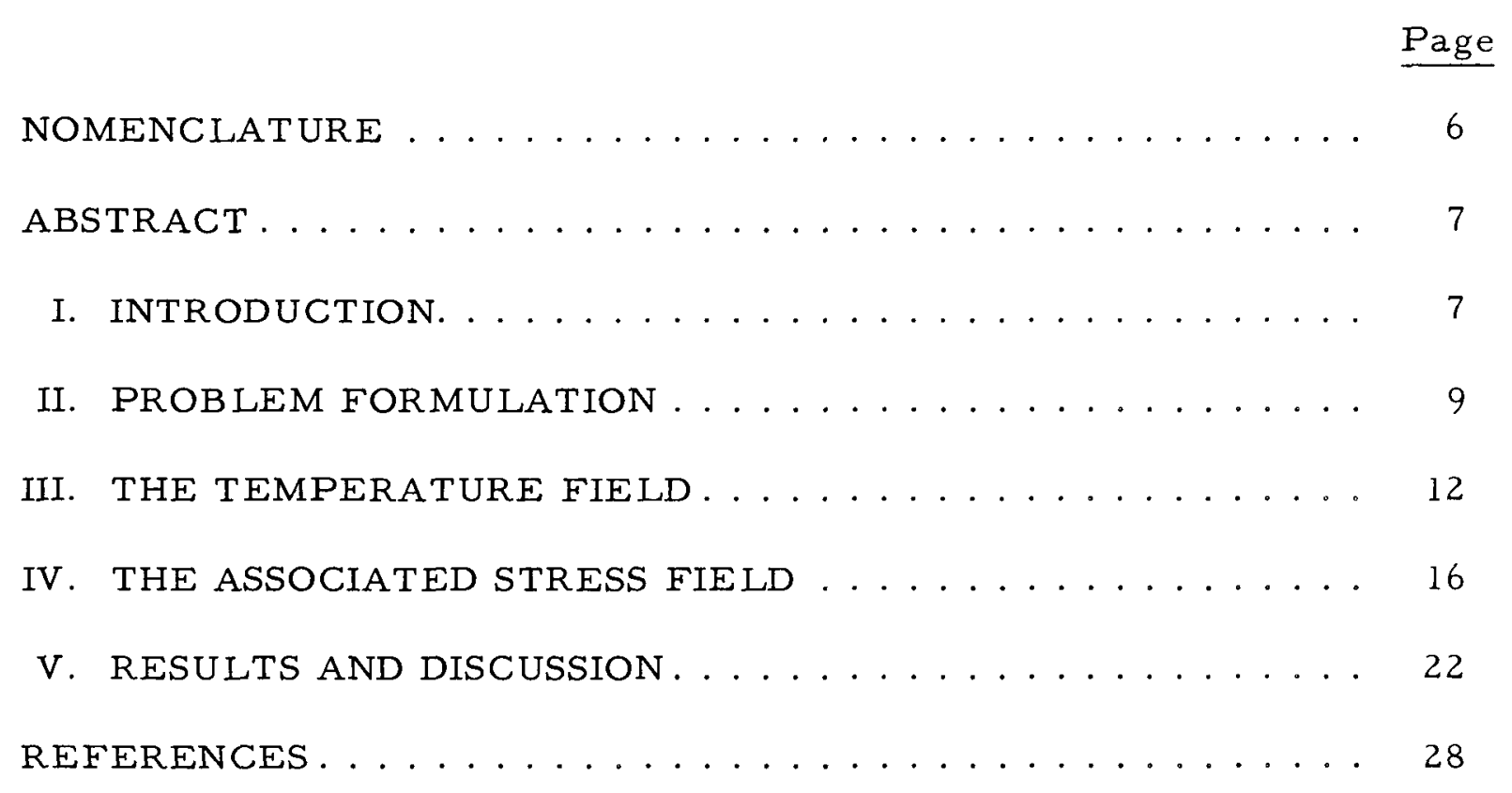




\section{LIST OF FIGURES}

No.

$\underline{\text { Title }}$

Page

1. Temperature at $\rho=0$ and $\rho=1$ as a Function of $\zeta$ for Various Values of $\tau ; \mathrm{m}=10, \beta=4.0 \ldots \ldots \ldots$

2. Circumferential Stress at $\rho=0$ and $\rho=1$ as a Function of $\zeta$ for Various Values of $\tau ; \mathrm{m}=10, \beta=4.0 \ldots \ldots$

3. Axial Stress at $\rho=0$ and $\rho=1$ as a Function of $\zeta$ for Various Values of $\tau ; \mathrm{m}=10, \beta=4.0 \ldots \ldots$

4. Shear Stress at $\rho=0.5$ as a Function of $\zeta$ for Various Values of $\tau ; \mathrm{m}=10, \beta=4.0 \ldots \ldots \ldots$

5. Temperature at $\rho=0$ and $\rho=1$ as a Function of $\zeta$ for Various Values of $\tau ; \mathrm{m}=0.1, \beta=4.0 \ldots \ldots$

6. Circumferential Stress at $\rho=0$ and $\rho=1$ as a Function of $\zeta$ for Various Values of $\tau ; \mathrm{m}=0.1, \beta=4.0 \ldots \ldots$

7. Axial Stress at $\rho=0$ and $\rho=1$ as a Function of $\zeta$ for Various Values of $\tau ; m=0.1, \beta=4.0 \ldots \ldots$

8. Shear Stress at $\rho=0.5$ as a Function of $\zeta$ for Various Values of $\tau ; \mathrm{m}=0.1, \beta=4.0 \ldots \ldots \ldots \ldots$

9. Temperature at $\rho=0$ and $\rho=1$ as a Function of $\zeta$ for Various Values of $\tau ; \mathrm{m}=10.0, \beta=0.5 \ldots \ldots$

10. Circumferential Stress at $\rho=0$ and $\rho=1$ as a Function of $\zeta$ for Various Values of $\tau ; \mathrm{m}=10.0, \beta=0.5 \ldots \ldots 26$

11. Axial Stress at $\rho=0$ and $\rho=1$ as a Function of $\zeta$ for Various Values of $\tau ; \mathrm{m}=10.0, \beta=0.5 \ldots \ldots \ldots$

12. Shear Stress at $p=0.5$ as a Function of $\zeta$ for Various Values

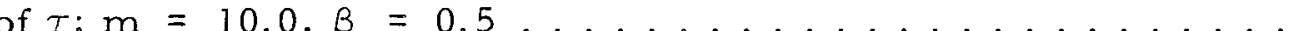

13. Temperature at $\rho=0$ and $\rho=1$ as a Function of $\zeta$ for Various Values of $\tau ; \mathrm{m}=0.1, \beta=0.5 \ldots \ldots$

14. Circumferential Stress at $\rho=0$ and $\rho=1$ as a Function of $\zeta$ for Various Values of $\tau ; \mathrm{m}=0.1, \beta=0.5 \ldots \ldots$

15. Axial Stress at $\rho=0$ and $\rho=1$ as a Function of $\zeta$ for Various Values of $7 ; \mathrm{m}=0.1, \beta=0.5 \ldots \ldots$

16. Shear Stress at $\rho=0.5$ as a Function of $\zeta$ for Various Values of $\tau ; \mathrm{m}=0.1, \beta=0.5 \ldots \ldots \ldots$ 
NOMENCLATURE

\begin{tabular}{|c|c|c|c|}
\hline Symbol & Description & Symbol & Description \\
\hline a & Outer radius of cylinder & $\mathrm{T}$ & Temperature \\
\hline b & Half-length of heat-generating segment & $\mathrm{T}_{0}$ & Constant reference temperature \\
\hline c & Specific heat & $\alpha$ & Coefficient of thermal expansion \\
\hline $\mathrm{f}$ & Function defined following Eq. 16 & $\beta$ & $\begin{array}{l}\text { Dimensionless half-length of heat- } \\
\text { generating segment }\end{array}$ \\
\hline h & Heat-transfer coefficient at boundary & $\gamma_{1}, \gamma_{2}$ & Auxiliary variables defined by Eq 31 \\
\hline $\mathrm{m}$ & Thermal conductivity & $\triangle$ & Function defined following Eq 45 \\
\hline$p$ & Fourier cosine transform variable & $\zeta$ & Dimensionless axial coordinate \\
\hline$q$ & Laplace transform variable & $\eta$ & Heaviside function \\
\hline $\mathbf{r}$ & Radial coordinate & $\theta$ & Circumferential coordinate \\
\hline & Tame & $\kappa$ & Thermal diffusivity \\
\hline$u_{r}, u_{z}$ & Radial and axial displacement functions & $\mu_{1}$ & Auxiliary variable defined by Eq. 31 \\
\hline$z$ & Axial coordinate & $\nu$ & Poisson's ratio \\
\hline$A, B, C$ & Functions defined by Eqs. $43-45$ & $\xi_{1}$ & Roots of Eq 22 \\
\hline$D_{1}$ & Function defined by Eq. 50 & $\rho$ & Dimensionless radıal coordınate \\
\hline $\mathrm{E}_{1}$ & Function defined by Eq 55 & $\bar{\rho}$ & Density \\
\hline $\mathrm{E}$ & Young's modulus & $\sigma_{r \mathrm{r}}^{\prime}$ & Stress components \\
\hline $\begin{array}{l}F_{1} \\
I_{0}, I_{1}\end{array}$ & $\begin{array}{l}\text { Function defined by Eq } 30 \\
\text { Modified Bessel functions of first kind }\end{array}$ & $\Phi, \Omega$ & $\begin{array}{l}\text { Dimensionless time } \\
\text { Stress functions defined by Eq. } 9\end{array}$ \\
\hline$J_{0}, J_{1}$ & Bessel functions of first kınd & $\begin{array}{l}\chi \\
\hat{\hat{T}} \hat{T}\end{array}$ & Love function \\
\hline Q & Heat-generation function & $\bar{\Phi}, \overline{\mathrm{T}}$, etc. & $\begin{array}{l}\text { Dimensionless forms of } \Phi, T \text {, etc. } \\
\text { Laplace transform of } \Phi, T \text {, etc }\end{array}$ \\
\hline$=$ & 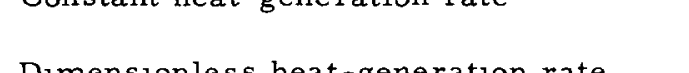 & $\tilde{\Phi}, \tilde{T}$, etc & Fourier cosine transform of $\Phi, T$, et \\
\hline
\end{tabular}




\begin{abstract}
TRANSIENT THERMAL STRESSES
ASSOCIATED WITH SUDDEN INITIATION

OF INTERNAL HEAT GENERATION IN A

SEGMENT OF A CIRCULAR CYLINDER
\end{abstract}

by

\author{
Richard A. Valentin \\ and Daniel F. Schoeberle
}

\begin{abstract}
An exact solution is given for the quasi-static thermalstress field associated with the transient temperatures arising when an infinite, homogeneous, isotropic, right circular cylinder, cooled at its surface by a temperature-independent boundary conductance, suddenly begins, and thereafter maintains, uniform internal heat generation within a finite axial region. The problem is of interest in certain nuclear-reactor analyses related to the behavior of fuel elements during power transients. The solution form is well suited to numerical evaluation, and extensive numerical results are given.
\end{abstract}

\title{
I. INTRODUCTION
}

The solution of three-dimensional thermoelasticity problems associated with distributed volumetric heat sources, while certainly not unique to the design and evaluation of nuclear-reactor components, could reasonably be expected to occur frequently in the specialized literature of the reactor field. That this is not necessarily the case is revealed by examining commonly used monographs such as Zudans et al. ${ }^{1}$ and design information such as that contained in the Reactor Handbook. ${ }^{2}$ Component geometry and details of the neutron flux justify the use of elementary plane stress and plane strain formulations in many cases. However, even allowing for this, the number of solved three-dimensional steady-state and transient problems involving internal heat generation is quite small. With the exception of a few papers, such as Burgreen ${ }^{3}$ and Kolesov, ${ }^{4}$ related to transient behavior of small, homogeneous, fast systems, elasticity problems occurring in reactor design seem to have immediately spawned computer codes. Although this trend toward computer solutions may be explained in part by the his torical importance and necessity of computers in reactor physics, it has resulted in a dearth of exact solutions and a tendency to immediately apply finite-difference methods in all but the most elementary situations. 
The present work, beyond its value as an approximation to certain physical situations occurring in reactor fuel rods during power transients, illustrates the type of exact solution that can be provided as a "module" in large safety-analysis codes to replace thermal-stress subroutines requir ing extensive storage and long execution times. In addition, this report gives a convenient set of known results for preliminary testing of comprehensive codes applicable to those situations whose complexity precludes exact analysis.

The problem to be treated concerns the transient temperature field and associated stress field caused by sudden initiation of uniform internal heat generation in an axial segment of an infinite right circular cylinder. The cylinder is homogeneous, isotropic, traction-free, and cooled at the surface through a temperature-independent boundary conductance. The assumed step function of time in the heat-generation rate cannot be realized by any physical process occurring within a reactor; however, it has value as an extreme limiting case. In addition, more realistic problems may be treated by the usual convolution integral applied to this solution and to any time variation of power for which the neutron flux (and hence the heat generation) is separable in time and space. The axial jump in heat-generation rate is also unrealistic but may be regarded as an approximation to the axial variation near a partially inserted bank of strong control rods, or as a model of behavior expected from a fuel pin having uneven axial fuel enrichment.

The solution presented assumes time and temperature independence of all occurring material properties and is exact within the framework of classical quasi-static thermoelasticity theory. Neglect of coupling and inertia effects is in part justified by well-known results in dynamic thermoelasticity (e.g., Nowacki, ${ }^{7}$ p. 262), and by the smoothness to be expected of the temperature field in both time and space. In some details, the solution resembles one obtained by Youngdahl and Sternberg ${ }^{5}$ for the transient stress field in a cylinder resulting from a sudden uniform change of surface temperature over a finite band. However, in addition to the obvious differences of internal heat generation and surface cooling through a boundary conductance, the stress-function formulation is different. Rather than the Papkovich-Neuber functions, application is made of stress functions closely related to the Love function and associated with the name of Hoyle. ${ }^{6}$

The temperature field is determined by combined use of Fourier cosine, Laplace, and finite Hankel transforms in axial position, time, and radial position, respectively. Solution of the associated stress problem then follows from the equations defining the Hoyle stress functions and the boundary conditions of zero surface traction. The stress functions, displacements, and stresses are expressed as a combination of series and integral expressions involving only elementary functions, Bessel functions, 
and the complementary error function. Numerical results are given for the temperature and stress components at the cylinder centerline and surface as a function of time and axial position for various combinations of the Biot number and length of the heat-generating segment.

\section{PROBLEM FORMULATION}

The heat conduction and associated thermoelasticity problems described in the introduction are conveniently referred to cylindrical coordinates $(r, \theta, z)$ in which $r, \theta$, and $z$ are, respectively, the radial, circumferential, and axial coordinates. The rotational symmetry of the problem ensures that all field quantities are independent of the circumfer ential coordinate, $\theta$. Determination of the temperature field requires solution of the equation of heat conduction,

$$
\kappa\left(\frac{\partial^{2} \mathrm{~T}}{\partial \mathrm{r}^{2}}+\frac{1}{\mathrm{r}} \frac{\partial \mathrm{T}}{\partial \mathrm{r}}+\frac{\partial^{2} \mathrm{~T}}{\partial \mathrm{z}^{2}}\right)+\frac{Q}{\bar{\partial} \mathrm{c}}=\frac{\partial \mathrm{T}}{\partial \mathrm{t}}
$$

for $0<\mathrm{t}<\infty$ in the cylindrical region $0 \leq \mathrm{r} \leq \mathrm{a},-\infty<\mathrm{z}<\infty$. In Eq. 1, the constants $\kappa, \bar{p}$, and $c$ are the thermal diffusivity, density, and specific heat, respectively, of the cylinder; $Q$ is the heat-generation rate per unit volume as a function of position and time. It is assumed that the cylinder, initially at uniform temperature $\mathrm{T}_{0}$, suddenly begins uniform internal heat generation at the constant rate $Q_{1}$ in the axial segment between $z=-b$ and $z=b$, the heat-generation rate being zero in the remainder of the cylinder. Heat is lost to a surrounding medium of constant temperature $\mathrm{T}_{0}$ through a temperature-independent boundary conductance, $h$.

From the above description, the heat-conduction problem is specified by the initial and boundary conditions

$$
\left.\begin{array}{l}
\mathrm{T}(\mathrm{r}, \mathrm{z}, 0)=\mathrm{T}_{0}, \quad 0 \leq \mathrm{r} \leq \mathrm{a}, \quad-\infty<\mathrm{z}<\infty, \\
\left.\mathrm{k}\left(\frac{\partial \mathrm{T}}{\partial \mathrm{r}}\right)=\mathrm{h}\left(\mathrm{T}_{0}-\mathrm{T}\right), \quad \mathrm{r}=\mathrm{a}, \quad-\infty<\mathrm{z}<\infty, \quad 0<\mathrm{t}<\infty, \quad\right\}
\end{array}\right\}
$$

to which must be appended the regularity condition

$$
\mathrm{T} \rightarrow \mathrm{T}_{0} \text { as }|\mathrm{z}| \rightarrow \infty, \quad 0<\mathrm{t}<\infty, \quad 0 \leq \mathrm{r} \leq \mathrm{a},
$$

and the definition of the heat-generation function

$$
Q=Q_{1} \eta(t) \eta(b-j z \mid),
$$

where $\eta(\cdot)$ is the usual Heaviside function. It is convenient to introduce dimensionless quantities defined by 


$$
\left.\begin{array}{l}
\rho=\mathrm{r} / \mathrm{a}, \quad \zeta=\mathrm{z} / \mathrm{a}, \quad \tau=\frac{\kappa \mathrm{t}}{\mathrm{a}^{2}}, \\
\mathrm{~T}(\mathrm{r}, \mathrm{z}, \mathrm{t})=\mathrm{T}_{0}[1+\overline{\mathrm{Q}} \hat{\mathrm{T}}(\rho, \zeta, \tau)], \\
\overline{\mathrm{Q}}=\frac{\mathrm{Q}_{1} \mathrm{a}^{2}}{\mathrm{kT}_{0}}, \quad \mathrm{~m}=\frac{\mathrm{ha}}{\mathrm{k}}, \quad \beta=\mathrm{b} / \mathrm{a} .
\end{array}\right\}
$$

From Eqs. 1, 4, and 5, the heat-conduction equation becomes

$$
\nabla^{2} \hat{\mathrm{T}}-\frac{\partial \hat{\mathrm{T}}}{\partial \tau}=-\eta(\beta-|\zeta|), \quad(0 \leq \rho \leq 1,-\infty<\zeta<\infty, 0<\tau<\infty)
$$

where

$$
\nabla^{2}=\frac{\partial^{2}}{\partial \rho^{2}}+\frac{1}{\rho} \frac{\partial}{\partial \rho}+\frac{\partial^{2}}{\partial \zeta^{2}}
$$

while the initial, boundary, and regularity conditions (Eqs. 2 and 3 ) become

$$
\left.\begin{array}{l}
\hat{\mathrm{T}}(\rho, \zeta, 0)=0, \quad 0 \leq \rho \leq 1, \quad-\infty<\zeta<\infty, \\
\left(\frac{\partial \hat{\mathrm{T}}}{\partial \rho}+\mathrm{m} \hat{\mathrm{T}}\right)_{\rho=1}=0, \quad-\infty<\zeta<\infty, \quad 0<\tau<\infty, \\
\hat{\mathrm{T}} \rightarrow 0 \text { as }|\zeta|_{\rightarrow \infty}, \quad 0 \leq \rho \leq 1, \quad 0<\tau<\infty .
\end{array}\right\}
$$

The thermoelasticity problem associated with the temperature field satisfying Eqs. 6 and 7 can be solved in terms of appropriately generalized Papkovich-Neuber stress functions. However, an alternate approach is possible using a set of stress functions discussed by Hoyle. ${ }^{6}$ The latter functions are closely related to the Love formulation of rotationally symmetric isothermal problems and have a slight advantage over the PapkovichNeuber form in the amount of algebraic manipulation required to generate the stress field. ${ }^{+}$

By including a rotationally symmetric temperature field in the classical derivation of the Love function as found in Love (Ref. 9, p. 274), we can represent the displacement and stress fields in terms of two functions satisfying

$\frac{\partial^{2} \Omega}{\partial r^{2}}+\frac{1}{r} \frac{\partial \Omega}{\partial r}+\frac{\partial^{2} \Omega}{\partial z^{2}}=0 ; \quad \frac{\partial^{2} \Phi}{\partial r^{2}}+\frac{1}{r} \frac{\partial \Phi}{\partial r}+\frac{\partial^{2} \Phi}{\partial z^{2}}=\frac{1}{1-\nu}\left(\frac{\partial^{2} \Omega}{\partial z^{2}}-\alpha E T\right)$.

${ }_{\text {An }}$ additional motivation for this choice of stress functions is the added convenience in comparing the isotropic solution with that for a transversely isotropic solid. The transversely isotropic case can be handled by a stressfunction formulation of Singh, ${ }^{8}$ which is a direct analog of that used in this report. 
In the absence of a nonuniform temperature field, the Love function, $\chi$, may be defined in terms of $\Phi$ and $\Omega$ through $\partial \chi / \partial z=\Phi+\Omega$ and all displacements and stresses expressed in terms of $\chi$ alone. However, for nonuniform $T$, this reduction to a single stress function is not possible. If the dimensionless stress functions $\hat{\Omega}$ and $\hat{\Phi}$ are defined by

$$
\Omega=\frac{a^{2} E \alpha T_{0} \bar{Q}}{1-\nu} \hat{\Omega}
$$

and

$$
\Phi=\frac{a^{2} E \alpha T_{0} \bar{Q}}{1-\nu} \hat{\Phi},
$$

then Eq. 8 becomes

$$
\left.\begin{array}{l}
\nabla^{2} \hat{\Omega}=0, \\
\nabla^{2} \hat{\Phi}=\frac{1}{1-\nu} \frac{\partial^{2} \hat{\Omega}}{\partial \zeta^{2}}-\hat{T} \\
(0 \leq \rho \leq 1,-\infty<\zeta<\infty, 0<\tau<\infty),
\end{array}\right\}
$$

and, with the dimensionless displacements and stresses $\hat{\mathrm{u}}_{\mathrm{r}}, \hat{\mathrm{u}}_{\mathrm{z}}, \hat{\sigma}_{\mathrm{rr}}, \hat{\sigma}_{\theta \theta}$, $\hat{\sigma}_{z z}$, and $\hat{\sigma}_{\mathrm{rz}}$ related to the actual components by

$$
\left.\begin{array}{l}
u_{r}(r, z, t)=\frac{1+\nu}{1-\nu} a \alpha T_{0} \bar{Q} \hat{u}_{r}(\rho, \zeta, \tau), \ldots, \\
\sigma_{r r}(r, z, t)=\frac{E \alpha T_{0} \bar{Q}}{1-\nu} \hat{\sigma}_{r r}(\rho, \zeta, \tau), \ldots, \ldots, \ldots,
\end{array}\right\}
$$

the displacement and stress fields are obtained from

$$
\begin{aligned}
& \hat{\mathbf{u}}_{\mathbf{r}}=-\frac{\partial \hat{\Omega}}{\partial \rho}-\frac{\partial \hat{\Phi}}{\partial \rho}, \\
& \left.\hat{\mathbf{u}}_{\mathrm{z}}=\frac{\partial \hat{\Omega}}{\partial \zeta}-\frac{\partial \hat{\Phi}}{\partial \zeta}, \quad\right\} \\
& \hat{\sigma}_{\mathrm{rr}}=\frac{\partial^{2} \hat{\Phi}}{\partial \zeta^{2}}+\frac{1}{\rho}\left(\frac{\partial \hat{\Phi}}{\partial \rho}+\frac{\partial \hat{\Omega}}{\partial \rho}\right) \\
& \hat{\sigma}_{\theta \theta}=\nu \nabla^{2} \hat{\Phi}-\frac{1}{\rho}\left(\frac{\partial \hat{\Phi}}{\partial \rho}+\frac{\partial \hat{\Omega}}{\partial \rho}\right)-(1-\nu) \hat{\mathrm{T}}, \\
& \hat{\sigma}_{\mathbf{z z}}=\frac{\partial^{2} \hat{\Phi}}{\partial \rho^{2}}+\frac{1}{\rho} \frac{\partial \hat{\Phi}}{\partial \rho} \text {. } \\
& \hat{\sigma}_{\mathbf{r z}}=-\frac{\partial^{2} \hat{\Phi}}{\partial \rho \partial \zeta} \text {. }
\end{aligned}
$$


Since the surface of the cylinder is assumed traction-free, the boundary conditions on the stress field are

$$
\begin{aligned}
& \hat{\sigma}_{\mathrm{rr}}(1, \zeta, \tau)=0, \quad \hat{\sigma}_{\mathrm{rz}}(1, \zeta, \tau)=0 \\
& (-\infty<\zeta<\infty, 0<\tau<\infty),
\end{aligned}
$$

and, in addition, it is necessary that

$$
\hat{\sigma}_{\mathrm{rr}}, \hat{\sigma}_{\theta \theta}, \hat{\sigma}_{\mathrm{zz}}, \hat{\sigma}_{\mathrm{rz}} \rightarrow 0 \text { as }|\zeta| \rightarrow \infty .
$$

The solution of the thermoelasticity problem associated with the temperature field satisfying Eqs. 6 and 7 thus requires the determination of functions $\hat{\Omega}$ and $\hat{\Phi}$ satisfying Eq. 9 subject to the boundary conditions implied by Eqs. 12, 13, and 14 .

\section{THE TEMPERATURE FIELD}

Considering the evident symmetry of the temperature field about the plane $\zeta=0$ and the assumed regularity conditions on the solution, the Fourier cosine transform

$$
\tilde{\mathrm{T}}(\rho, \mathrm{p}, \tau)=\left(\frac{2}{\pi}\right)^{1 / 2} \int_{0}^{\infty} \hat{\mathrm{T}}(\rho, \zeta, \tau) \cos \mathrm{p} \zeta \mathrm{d} \zeta,
$$

when applied to Eq. 6 yields

$$
\nabla_{1}^{2} \ddot{T}-p^{2} \tilde{T}-\frac{\partial \tilde{T}}{\partial \tau}=-f(p)
$$

where

$$
\nabla_{1}^{2}=\frac{\partial^{2}}{\partial \rho^{2}}+\frac{1}{\rho} \frac{\partial}{\partial \rho}
$$

and

$$
f(p)=\left(\frac{2}{\pi}\right)^{1 / 2} \frac{\sin p \beta}{p}
$$

The initial and boundary conditions (Eqs. 7) transform to

$$
\left.\begin{array}{l}
\tilde{\mathrm{T}}(\rho, \mathrm{p}, 0)=0, \quad 0 \leq \rho \leq 1, \\
\frac{\partial \tilde{\mathrm{T}}}{\partial \rho}+\mathrm{m} \tilde{\mathrm{T}}=0, \quad \rho=1, \quad 0<\tau<\infty .
\end{array}\right\}
$$


Applying the Laplace transform,

$$
\bar{T}(\rho, p, q)=\int_{0}^{\infty} \tilde{T}(\rho, p, \tau) \exp (-q \tau) d \tau
$$

to Eqs. 16 and 17 then implies

$$
\nabla_{1}^{2} \overline{\mathrm{T}}-\left(\mathrm{p}^{2}+\mathrm{q}\right) \overline{\mathrm{T}}=-\mathrm{q}^{-1} \mathrm{f}(\mathrm{p}), \quad 0 \leq \rho \leq 1,
$$

with the boundary condition.

$$
\frac{\partial \overline{\mathrm{T}}}{\partial \rho}+\mathrm{m} \overline{\mathrm{T}}=0, \quad \rho=1
$$

The most straightforward solution of Eqs. 19 and 20 follows from the application of the finite Hankel transform of zero order, ${ }^{10}$

$$
\mathrm{T}^{*}\left(\xi_{\mathrm{i}}, \mathrm{p}, \mathrm{q}\right)=\int_{0}^{1} \rho \overline{\mathrm{T}}(\rho, \mathrm{p}, \mathrm{q}) \mathrm{J}_{0}\left(\rho \xi_{\mathrm{i}}\right) \mathrm{d} \rho
$$

where $\xi_{i}$ are the positive, real roots of

$$
\mathrm{mJ}_{0}(\xi)=\xi \mathrm{J}_{1}(\xi)
$$

The Hankel transform (Eq. 21), when applied to Eq. 19 together with the transformation properties of the $\nabla_{1}^{2}$ operator and the integral

$$
\int_{0}^{1} \rho J_{0}\left(\rho \xi_{i}\right) d p=\xi_{i}^{-1} J_{1}(\xi)
$$

immediately yields the transformed solution

$$
T^{*}\left(\xi_{i}, p, q\right)=\frac{f(p) J_{1}\left(\xi_{i}\right)}{q\left(\xi_{i}^{2}+p^{2}+q\right) \xi_{i}}
$$

The inversion formula for the zero-order finite Hankel transform (Ref. 10, p. 84),

$$
\overline{\mathrm{T}}(\rho, \mathrm{p}, \mathrm{q})=2 \sum_{\mathrm{i}} \frac{\xi_{\mathrm{i}}^{2} \mathrm{~T} *\left(\xi_{\mathrm{i}}, \mathrm{p}, \mathrm{q}\right) \mathrm{J}_{0}\left(\rho \xi_{\mathrm{i}}\right)}{\left(\mathrm{m}^{2}+\xi_{i}^{2}\right) \mathrm{J}_{0}^{2}\left(\xi_{i}\right)}
$$

and Eqs. 22 and 23 give

$$
\overline{\mathrm{T}}(\rho, p, q)=2 \mathrm{~m} \sum_{i} \frac{f(p) J_{0}\left(\rho \xi_{i}\right)}{\left(\mathrm{m}^{2}+\xi_{i}^{2}\right)\left(\xi_{i}^{2}+p^{2}+q\right) q J_{0}\left(\xi_{i}\right)} .
$$


The inversion of the Laplace transform is, formally, a simple matter in Eq. 24 and gives

$$
\tilde{\mathrm{T}}(\rho, \mathrm{p}, \tau)=2 \mathrm{~m} \sum_{i} \frac{f(\mathrm{p})\left\{\mathrm{l}-\exp \left[-\left(\mathrm{p}^{2}+\xi_{i}^{2}\right) \tau\right]\right\} J_{0}\left(\rho \xi_{i}\right)}{\left(\mathrm{p}^{2}+\xi_{i}^{2}\right)\left(\mathrm{m}^{2}+\xi_{i}^{2}\right) J_{0}\left(\xi_{i}\right)} .
$$

Inversion of the remaining Fourier cosine transform, using

$$
\hat{\mathrm{T}}(\rho, \zeta, \tau)=\left(\frac{2}{\pi}\right)^{1 / 2} \int_{0}^{\infty} \tilde{\mathrm{T}}(\rho, \mathrm{p}, \tau) \cos \mathrm{p} \zeta \mathrm{dp}
$$

and Eq. 25, then yields

$$
\hat{\mathrm{T}}(\rho, \zeta, \tau)=\hat{\mathrm{T}}_{1}(\rho, \zeta)+\hat{\mathrm{T}}_{2}(\rho, \zeta, \tau),
$$

where

$$
\hat{\mathrm{T}}_{1}(\rho, \zeta)=\frac{4 \mathrm{~m}}{\pi} \sum_{i} \frac{\mathrm{J}_{0}\left(\rho \xi_{\mathrm{i}}\right)}{\left(\mathrm{m}^{2}+\xi_{i}^{2}\right) \mathrm{J}_{0}\left(\xi_{i}\right)} \int_{0}^{\infty} \frac{\sin \mathrm{p} \beta \cos \mathrm{p} \zeta}{\mathrm{p}\left(\mathrm{p}^{2}+\xi_{i}^{2}\right)} \mathrm{dp},
$$

and

$$
\hat{\mathrm{T}}_{2}(\rho, \zeta, \tau)=-\frac{4 \mathrm{~m}}{\pi} \sum \frac{\mathrm{J}_{0}\left(\rho \xi_{i}\right)}{\left(\mathrm{m}^{2}+\xi_{i}^{2}\right) J_{0}\left(\xi_{i}\right)} \int_{0}^{\infty} \frac{\sin \mathrm{p} \beta \cos \mathrm{p} \zeta \exp \left[-\left(\mathrm{p}^{2}+\xi_{i}^{2}\right) \tau\right]}{\mathrm{p}\left(\mathrm{p}^{2}+\xi_{i}^{2}\right)} \mathrm{dp} .
$$

Several of the operations used to obtain Eqs. 27 and 28 are only valid in a formal sense. However, these manipulations and several of a similar nature to follow are justified in the final validation of the solution by substitution into the original equations and by investigation of the convergence of the various series representations.

The improper integrals in Eqs. 27 and 28 may be evaluated by reference to standard integral tables. For example, the integral in Eq. 27, upon comparison with integrals 3.741 .2 and 3.742 .5 of Ref. 11, immediately yields

$$
\int_{0}^{\infty} \frac{\sin \beta p \cos p \zeta}{p\left(p^{2}+\xi_{i}^{2}\right)} d p= \begin{cases}\frac{\pi}{2 \xi_{i}^{2}}\left[1-\exp \left(-\beta \xi_{i}\right) \cosh \zeta \xi_{i}\right], & \zeta<\beta, \\ \frac{\pi}{2 \xi_{i}^{2}} \exp \left(-\zeta \xi_{i}\right) \sinh \beta \xi_{i}, \quad \zeta>\beta .\end{cases}
$$


To evaluate the integral in Eq. 28, one uses the factorization

$$
\begin{aligned}
F_{i}(\zeta, \tau) \equiv & \int_{0}^{\infty} \frac{\sin \mathrm{p} \beta \cos \mathrm{p} \zeta \exp \left[-\left(\mathrm{p}^{2}+\xi_{\mathrm{i}}^{2}\right) \tau\right]}{\mathrm{p}\left(\mathrm{p}^{2}+\xi_{\mathrm{i}}^{2}\right)} \mathrm{dp} \\
= & \xi_{\mathrm{i}}^{-2} \exp \left(-\xi_{\mathrm{i}}^{2} \tau\right)\left\{\int_{0}^{\infty} \mathrm{p}^{-1} \sin \beta \mathrm{p} \cos \mathrm{p} \zeta \exp \left(-\mathrm{p}^{2} \tau\right) \mathrm{dp}\right. \\
& \left.-\int_{0}^{(\infty)} \frac{\mathrm{p} \sin \mathrm{p} \beta \cos \mathrm{p} \zeta}{\mathrm{p}^{2}+\xi_{\mathrm{i}}^{2}} \exp \left(-\mathrm{p}^{2} \tau\right) \mathrm{dp}\right\},
\end{aligned}
$$

the identity $\sin \mathrm{p} \beta \cos \mathrm{p} \zeta=\frac{1}{2}[\sin \mathrm{p}(\beta+\zeta)+\sin \mathrm{p}(\beta-\zeta)]$, and the integrals 2.4 .21 and 2.4 .26 of Ref. 12 to give ${ }^{\dagger}$

$$
\begin{aligned}
F_{i}(\zeta, \tau)= & \frac{\pi}{8 \xi_{i}^{2}}\left\{\exp \left(2 \gamma_{1} \mu_{i}\right) \operatorname{erfc}\left(\gamma_{1}+\mu_{i}\right)-\exp \left(-2 \gamma_{1} \mu_{i}\right) \operatorname{erfc}\left(\gamma_{1}-\mu_{i}\right)\right. \\
& +\exp \left(2 \gamma_{2} \mu_{i}\right) \operatorname{erfc}\left(\gamma_{2}+\mu_{i}\right)-\exp \left(-2 \gamma_{2} \mu_{i}\right) \operatorname{erfc}\left(\gamma_{2}-\mu_{i}\right) \\
& \left.+2 \exp \left(-\xi_{i}^{2} \tau\right)\left[2-\operatorname{erfc}\left(\gamma_{1}\right)-\operatorname{erfc}\left(\gamma_{2}\right)\right]\right\},
\end{aligned}
$$

where the auxiliary variables

$$
\mu_{\mathrm{i}}=\xi_{\mathrm{i} \sqrt{\tau},} \quad \gamma_{1}=\frac{\beta+\zeta}{2 \sqrt{\tau}}, \quad \text { and } \gamma_{2}=\frac{\beta-\zeta}{2 \sqrt{\tau}}
$$

have been introduced. It is a simple, if somewhat tedious, matter to verify that the solution given by Eqs. 27-30 is a valid solution of Eqs. 6 and 7 and that convergence is assured within $0 \leq \rho \leq 1,-\infty<\zeta<\infty$ for all $\tau>0$.

Although Eqs. 27-30 are in an ideal form for the numerical evaluation of the temperature field, the solution of the associated thermoelasticity problem becomes somewhat easier if the steady-state portion of the solution, $\hat{T}_{1}(\rho, \zeta)$, is expressed as an integral. If one considers the steadystate problem

$$
\left.\begin{array}{l}
\nabla^{2} \hat{\mathrm{T}}_{1}=-\eta(\beta-|\zeta|), \quad 0 \leq \rho \leq 1, \quad-\infty<\zeta<\infty, \\
\left(\frac{\partial \hat{\mathrm{T}}_{1}}{\partial \rho}+\mathrm{m} \hat{\mathrm{T}}_{1}\right)_{\rho=1}=0, \quad-\infty<\zeta<\infty, \\
\hat{\mathrm{T}}_{1 \rightarrow 0 \text { as }|\zeta| \rightarrow \infty,} \quad 0 \leq \rho \leq 1,
\end{array}\right\}
$$

\footnotetext{
In the evaluation of this integral, it was noted that the integrals 3.954 .1 and 3.954 .2 of Ref. 11 were incorrectly transcribed from 2.4 .26 and 1.4 .15 of Ref. 12 . Equation 30 may also be taken directly from Eq. 48 of Ref. 5.
} 
and applies the Fourier cosine transform to obtain

$$
\left.\begin{array}{l}
\nabla_{1}^{2} \tilde{\mathrm{T}}_{1}-\mathrm{p}^{2} \tilde{\mathrm{T}}_{1}=-\mathrm{f}(\mathrm{p}), \quad 0 \leq \rho \leq 1, \\
\left(\frac{\partial \tilde{\mathrm{T}}_{1}}{\partial \rho}+\mathrm{m} \tilde{\mathrm{T}}_{1}\right)_{\rho=1}=0,
\end{array}\right\}
$$

the solution of the transformed problem may be immediately written as

$$
\widetilde{T}_{1}(\rho, p)=\frac{f(p)\left\{p I_{1}(p)+m\left[I_{0}(p)-I_{0}(p \rho)\right]\right\}}{p^{2}\left[p I_{1}(p)+m I_{0}(p)\right]}
$$

which, upon inversion of the cosine transform, yields

$$
\hat{\mathrm{T}}_{1}(\rho, \zeta)=\frac{2}{\pi} \int_{0}^{\infty} \frac{\sin \mathrm{p} \beta \cos \mathrm{p} \zeta\left\{\mathrm{pI}_{1}(\mathrm{p})+\mathrm{m}\left[\mathrm{I}_{0}(\mathrm{p})-\mathrm{I}_{0}(\mathrm{p} \rho)\right]\right\}}{\mathrm{p}^{3}\left[\mathrm{pI} \mathrm{I}_{1}(\mathrm{p})+\mathrm{mI}_{0}(\mathrm{p})\right]} \mathrm{dp} .
$$

The complete equivalence of Eq. 34 and Eqs. 27 and 29 may be demonstrated by standard complex-variable methods applied to Eq. 34 . In çonsidering the stress-function equations Eqs. 9, we shall thus as sume the temperature field to be given by

$$
\begin{aligned}
\hat{\mathrm{T}}(\rho, \zeta, \tau)= & \frac{2}{\pi} \int_{0}^{\infty} \frac{\sin \mathrm{p} \beta \cos \mathrm{p} \zeta\left\{\mathrm{pI} \mathrm{I}_{1}(\mathrm{p})+\mathrm{m}\left[\mathrm{I}_{0}(\mathrm{p})-\mathrm{I}_{0}(\mathrm{p} \rho)\right]\right\}}{\mathrm{p}^{3}\left[\mathrm{pI} \mathrm{I}_{1}(\mathrm{p})+\mathrm{mI} \mathrm{I}_{0}(\mathrm{p})\right]} \mathrm{dp} \\
& -\frac{4 \mathrm{~m}}{\pi} \int_{0}^{\infty} \frac{\sin \mathrm{p} \beta \cos \mathrm{p} \zeta}{\mathrm{p}} \sum_{\mathrm{i}} \frac{\mathrm{J}_{0}\left(\rho \xi_{\mathrm{i}}\right) \exp \left[-\left(\mathrm{p}^{2}+\xi_{\mathrm{i}}^{2}\right) \tau\right]}{\left(\mathrm{p}^{2}+\xi_{\mathrm{i}}^{2}\right)\left(\mathrm{m}^{2}+\xi_{i}^{2}\right) \mathrm{J}_{0}\left(\xi_{\mathrm{i}}^{2}\right)} \mathrm{dp},
\end{aligned}
$$

but for numerical evaluation, Eqs. 27-30 will be used.

\section{THE ASSOCIATED STRESS FIELD}

The associated thermoelasticity problem requires the determination of functions $\hat{\Omega}(\rho, \zeta, \tau)$ and $\hat{\Phi}(\rho, \zeta, \tau)$, finite at $\rho=0$, satisfying Eqs. 9 with the temperature field given by Eq. 35, and such that the stresses derived from Eq. 12 satisfy Eqs. 13 and 14. The solution of the first equation of Eqs. 9 is taken in the form

$$
\hat{\Omega}(\rho, \zeta, \tau)=\frac{2}{\pi} \int_{0}^{\infty} \sin \mathrm{p} \beta \cos \mathrm{p} \zeta \mathrm{I}_{0}(\mathrm{p} \rho) \mathrm{A}(\mathrm{p}, \tau) \mathrm{dp},
$$


where $\mathrm{A}(\mathrm{p}, \tau)$ is an as yet unknown function to be determined by the bound ary conditions in Eq. 13. The second equation of Eqs. 9 is assumed to have a solution

$$
\hat{\Phi}=\hat{\Phi}_{0}+\hat{\Phi}_{1}+\hat{\Phi}_{2}+\hat{\Phi}_{3} \text {, }
$$

where $\hat{\Phi}_{0}$ is harmonic and

and

$$
\begin{aligned}
& \nabla^{2} \hat{\Phi}_{1}=-\hat{\mathrm{T}}_{1}, \\
& \nabla^{2} \hat{\Phi}_{2}=-\hat{\mathrm{T}}_{2},
\end{aligned}
$$

Analogously to Eq. 36, the harmonic function $\hat{\Phi}_{0}(\rho, \zeta, \tau)$ has the representation

$$
\hat{\Phi}_{0}(\rho, \zeta, \tau)=\frac{2}{\pi} \int_{0}^{\infty} \sin \mathrm{p} \beta \cos \mathrm{p} \zeta \mathrm{I}_{0}(\mathrm{p} \rho) \mathrm{B}(\mathrm{p}, \tau) \mathrm{dp}
$$

where $\mathrm{B}(\mathrm{p}, \tau)$ is to be determined by Eq. 13. The particular solutions $\hat{\Phi}_{1}$, $\hat{\Phi}_{2}$, and $\hat{\Phi}_{3}$ are easily found by inspection of the equations resulting from application of the Fourier cosine transform in $\zeta$ to Eqs. 37. The appropriate particular solutions are given by

$$
\begin{aligned}
\hat{\Phi}_{1}(\rho, \zeta)= & \frac{1}{\pi} \int_{0}^{\infty} \frac{\sin \mathrm{p} \beta \cos \mathrm{p} \zeta}{\mathrm{p}^{5}\left[\mathrm{pI} \mathrm{I}_{1}(\mathrm{p})+\mathrm{mI} \mathrm{I}_{0}(\mathrm{p})\right]}\left\{m p \rho \mathrm{I}_{1}(\mathrm{p} \rho)\right. \\
& \left.+2\left[\mathrm{pI_{1 }}(\mathrm{p})+\mathrm{mI}_{0}(\mathrm{p})\right]-\left[2 \mathrm{~m}+\mathrm{p}^{2}(1+\mathrm{m} / 2)\right] \mathrm{I}_{0}(\mathrm{p} \rho)\right\} \mathrm{d} \mathrm{p}, \\
\hat{\Phi}_{2}(\rho, \zeta, \tau) & =-\frac{4 \mathrm{~m}}{\pi} \int_{0}^{\infty} \mathrm{p}^{-1} \sin \mathrm{p} \beta \cos \mathrm{p} \zeta \sum_{\mathrm{i}} \frac{\mathrm{J}_{0}\left(\rho \xi_{\mathrm{i}}\right) \exp \left[-\left(\mathrm{p}^{2}+\xi_{\mathrm{i}}^{2}\right) \tau\right]}{\left(\mathrm{p}^{2}+\xi_{\mathrm{i}}^{2}\right)^{2}\left(\mathrm{~m}^{2}+\xi_{\mathrm{i}}^{2}\right) \mathrm{J}_{0}\left(\xi_{\mathrm{i}}\right)} \mathrm{dp},
\end{aligned}
$$

and

$$
\hat{\Phi}_{3}(\rho, \zeta, \tau)=-\frac{1}{\pi(1-\nu)} \int_{0}^{\infty} \sin \mathrm{p} \beta \cos \mathrm{p} \zeta\left[\mathrm{p} \rho \mathrm{I}_{1}(\mathrm{p} \rho)\right] \mathrm{A}(\mathrm{p}, \tau) \mathrm{dp}
$$

Upon reference to the boundary conditions (Eq. 13) and Eq. 12, the functions $A(p, \tau)$ and $B(p, \tau)$ are to satisfy 


$$
\left.\begin{array}{l}
{\left[\frac{\partial^{2} \Phi}{\partial \zeta^{2}}+\frac{1}{\rho}\left(\frac{\partial \hat{\Phi}}{\partial \rho}+\frac{\partial \hat{\Phi}}{\partial \rho}\right)\right]_{\rho=1}=0,} \\
\left(\frac{\partial^{2} \hat{\Phi}}{\partial \rho \partial \zeta}\right)_{\rho=1}=0 .
\end{array}\right\}
$$

Substitution of Eqs. 38-40 into Eqs. 42, evaluation of the result at $\rho=1$, and the requirement that the integrands of the resulting integrals vanish, imply the following two conditions:

$$
\begin{aligned}
p I_{0}(p) A_{1}(p, \tau)-I_{1}(p) B_{1}(p, \tau)= & m p I_{0}(p)-\left[2 m+p^{2}(1+m / 2)\right] I_{1}(p) \\
& +4 m^{2} p^{3}\left[p I_{1}(p)+m I_{0}(p)\right] C(p, \tau)
\end{aligned}
$$

and

$$
\begin{aligned}
{\left[p^{2}+\right.} & 2(1-\nu)] I_{1}(p) A_{1}(p, \tau)-p I_{0}(p) B_{1}(p, \tau)=p^{2}(1+m / 2)\left[2 I_{1}(p)-p I_{0}(p)\right] \\
& -4 m p^{5}\left[p I_{1}(p)+m I_{0}(p)\right] C(p, \tau)
\end{aligned}
$$

where

$$
\begin{aligned}
& \mathrm{A}(\mathrm{p}, \tau)=\frac{(1-\nu) \mathrm{A}_{1}(\mathrm{p}, \tau)}{\mathrm{p}^{5}\left[\mathrm{pI}_{1}(\mathrm{p})+\mathrm{mI}_{0}(\mathrm{p})\right]}, \\
& \mathrm{B}(\mathrm{p}, \tau)=\frac{\mathrm{B}_{1}(\mathrm{p}, \tau)}{2 \mathrm{p}^{5}\left[\mathrm{pI}_{1}(\mathrm{p})+\mathrm{mI}_{0}(\mathrm{p})\right]},
\end{aligned}
$$

and

$$
C(\mathrm{p}, \tau)=\sum_{i} \frac{\exp \left[-\left(\mathrm{p}^{2}+\xi_{\mathrm{i}}^{2}\right) \tau\right]}{\left(\mathrm{p}^{2}+\xi_{i}^{2}\right)^{2}\left(\mathrm{~m}^{2}+\xi_{i}^{2}\right)}
$$

Solution of the pair of simultaneous equations (Eqs. 43) then yields

$$
\begin{aligned}
A(p, \tau)= & \frac{1-\nu}{p^{4} \Delta(p)\left[p I_{1}(p)+\mathrm{mI}_{0}(p)\right]}\left\{-m p I_{0}^{2}(p)+2 m I_{0}(p) I_{1}(p)+(m+2) p I_{1}^{2}(p)\right\} \\
& -\frac{4 m(1-\nu)}{p \Delta(p)}\left[p I_{1}(p)+m_{0}(p)\right] C(p, \tau)
\end{aligned}
$$

and

$$
\begin{aligned}
& B(p, \tau)=\frac{1}{2 p^{5} \Delta(\rho)\left[\rho I_{1}(p)+m I_{0}(p)\right]}\left\{-\rho^{4}(1+m / 2) I_{0}^{2}(p)+2\left[p^{2}-m(1-\nu)\right] \rho I_{0}(p) I_{1}(p)+\left[p^{2}+2(1-\nu)\right]\left[2 m+p^{2}(1+m / 2)\right] I_{1}^{2}(p)\right\} \\
& -\frac{2 m}{\rho^{2} \Delta(p)}\left\{\rho^{3} I_{0}(p)+m\left[p^{2}+2(1-v)\right] I_{1}(p)\right\} C(p, \tau) \text {, }
\end{aligned}
$$


where

$$
\Delta(p)=\left[p^{2}+2(1-\nu)\right] I_{1}^{2}(p)-p^{2} I_{0}^{2}(p)
$$

Substitution of Eqs. 44 and 45 into Eqs. 36 and $38-41$ gives the stress functions

$$
\begin{aligned}
\hat{\Omega}(\rho, \zeta, \tau)= & \frac{2(1-\nu)}{\pi} \int_{0}^{\infty} \frac{\sin p \beta \cos p \zeta I_{0}(p \rho)}{p^{4} \Delta(p)\left[p I_{1}(p)+m I_{0}(p)\right]}\left\{-\operatorname{mpI}_{0}^{2}(p)\right. \\
& \left.+2 m I_{0}(p) I_{1}(p)+(m+2) p I_{1}^{2}(p)\right\} d p \\
& -\frac{8 m(1-\nu)}{\pi} \int_{0}^{\infty} \frac{\sin p \beta \cos p \zeta}{p \Delta(p)}\left[p I_{1}(p)+m I_{0}(p)\right] C(p, \tau) d p,
\end{aligned}
$$

and

$$
\begin{aligned}
& \hat{\Phi}(\rho, \zeta, \tau)=\frac{2}{\pi} \int_{0}^{\infty} \frac{\sin \mathrm{p} \beta_{1} \cos \mathrm{p} \zeta}{\mathrm{p}^{5} \Delta(\mathrm{p})\left[\mathrm{pI} \mathrm{I}_{1}(\mathrm{p})+\mathrm{mI}_{0}(\mathrm{p})\right]}\left\{\left[\left[\mathrm{m}(1-\nu)-\mathrm{p}^{2}\right] \mathrm{I}_{1}(\mathrm{p})-\mathrm{mpI} \mathrm{I}_{0}(\mathrm{p})\right]\right. \\
& \text { - } \left.\left[p \rho I_{1}(p) I_{1}(p \rho)-p I_{0}(p) I_{0}(p \rho)\right]+\Delta(p)\left[p I_{1}(p)+m I_{0}(p)\right]\right\} d p \\
& -\frac{4 m}{\pi} \int_{0}^{\infty} \frac{\sin p \beta \cos p \zeta}{p^{2} \Delta(p)}\left\{I_{0}(p p)\left\{p^{3} I_{0}(p)+m\left(p^{2}+1-\nu\right) I_{1}(p)\right\}\right. \\
& \left.-\mathrm{p}^{2} \rho \mathrm{I}_{1}(\mathrm{p} \rho)\left[\mathrm{pI} \mathrm{I}_{1}(\mathrm{p})+\mathrm{mI}_{0}(\mathrm{p})\right]\right\} \mathrm{C}(\mathrm{p}, \tau) \mathrm{dp} \\
& -\frac{4 \mathrm{~m}}{\pi} \int_{0}^{\infty} \mathrm{p}^{-1} \sin \mathrm{p} \beta \cos \mathrm{p} \zeta \sum_{i} \frac{\mathrm{J}_{0}\left(\rho \xi_{\mathrm{i}}\right) \exp \left[-\left(\mathrm{p}^{2}+\xi_{\mathrm{i}}^{2}\right) \tau\right]}{\left(\mathrm{p}^{2}+\xi_{i}^{2}\right)^{2}\left(\mathrm{~m}^{2}+\xi_{i}^{2}\right) \mathrm{J}_{0}\left(\xi_{i}\right)} \mathrm{dp} \text {. }
\end{aligned}
$$

The integrals in Eq. 46 and the first two integrals of Eq. 47 are in a form suitable for numerical evaluation. However, the improper integral over the infinite series that constitutes the last part of Eq. 47 is inconvenient for numerical work and, hence, is first evaluated in closed form. Assuming an interchange of integration and summation is valid in the last term of Eq. 47, we must evaluate

$$
\mathrm{D}_{\mathrm{i}}(\zeta, \tau)=\int_{0}^{\infty} \frac{\sin \mathrm{p} \beta \cos \mathrm{p} \zeta \exp \left[-\left(\mathrm{p}^{2}+\xi_{i}^{2}\right) \tau\right]}{\mathrm{p}\left(\mathrm{p}^{2}+\xi_{i}^{2}\right)^{2}} \mathrm{dp} .
$$

This integral may be computed from Eq. 30 by noting that 


$$
D_{i}(\zeta, \tau)=-\frac{\exp \left(-\xi_{i}^{2} \tau\right)}{2 \xi_{i}} \frac{d}{d \xi_{i}}\left[\exp \left(\xi_{i}^{2} \tau\right) F_{i}(\zeta, \tau)\right],
$$

or, alternately, it may be taken directly from Eq. 78 of Ref. 5.

It is found that

$$
\begin{aligned}
D_{i}(\zeta, \tau)= & \frac{\pi}{8 \xi_{i}^{4}}\left\{\left(1-\mu_{i} \gamma_{1}-\mu_{i}^{2}\right) \exp \left(2 \mu_{i} \gamma_{1}\right) \operatorname{erfc}\left(\mu_{i}+\gamma_{1}\right)\right. \\
& -\left(1+\mu_{i} \gamma_{1}-\mu_{i}^{2}\right) \exp \left(-2 \mu_{i} \gamma_{1}\right) \operatorname{erfc}\left(\mu_{i}-\gamma_{1}\right) \\
& +\left(1-\mu_{i} \gamma_{2}-\mu_{i}^{2}\right) \exp \left(2 \mu_{i} \gamma_{2}\right) \operatorname{erfc}\left(\mu_{i}+\gamma_{2}\right) \\
& -\left(1+\mu_{i} \gamma_{2}-\mu_{i}^{2}\right) \exp \left(-2 \mu_{i} \gamma_{2}\right) \operatorname{erfc}\left(\mu_{i}-\gamma_{2}\right) \\
& \left.+2 \exp \left(-\xi_{i}^{2} \tau\right)\left[2-\operatorname{erfc}\left(\gamma_{1}\right)-\operatorname{erfc}\left(\gamma_{2}\right)\right]\right\},
\end{aligned}
$$

and the required stress functions are thus specified by Eqs. 46 and 47 together with Eq. 50. The generation of the stress field then follows by substitution of the stress functions (Eqs. 46 and 47) and the temperature field (Eq. 36) into Eqs. 12. The stresses then appear as

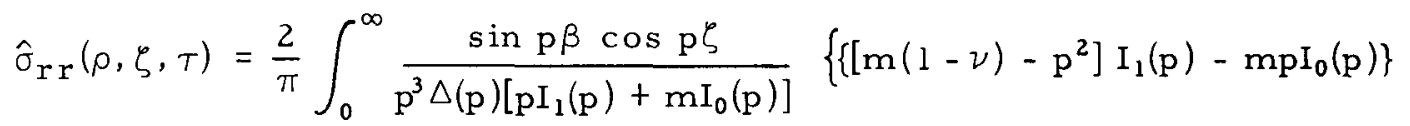

$$
\begin{aligned}
& \cdot\left\{I_{0}(p \rho)\left[p I_{0}(p)+I_{1}(p)\right]-p \rho I_{1}(p) I_{1}(p \rho)\right\} \\
& +\rho^{-1} I_{1}(p \rho)\left\{m \nu p I_{0}^{2}(p)+\left[m(1-\nu)+p^{2}\right] I_{0}(p) I_{1}(p)\right. \\
& \left.\left.+(1-\nu)(2+\mathrm{m}) \mathrm{pI}_{1}^{2}(\mathrm{p})\right\}-\Delta(\mathrm{p})\left[\mathrm{pI}_{1}(\mathrm{p})+\mathrm{mI}_{0}(\mathrm{p})\right]\right\} \mathrm{dp} \\
& +\frac{4 m}{\pi} \int_{0}^{\infty} \frac{\sin p \beta \cos p \zeta}{\Delta(p)} C(p, \tau)\left\{I _ { 0 } ( p \rho ) \left\{p\left(m+p^{2}\right) I_{0}(p)\right.\right. \\
& \left.+\left[2 \mathrm{~m}(1-\nu)+\mathrm{p}^{2}(\mathrm{~m}+1)\right] \mathrm{I}_{1}(\mathrm{p})\right\}-(\mathrm{p} \rho)^{-1} \mathrm{I}_{1}(\mathrm{p} \rho)\left\{\mathrm{p}\left[2 \mathrm{~m}(1-\nu)+\mathrm{p}^{2}\right] \mathrm{I}_{0}(\mathrm{p})\right. \\
& \left.\left.+\left[2 \mathrm{~m}(1-\nu)+\mathrm{p}^{2}[\mathrm{~m}+2(1-\nu)]\right] \mathrm{I}_{1}(\mathrm{p})\right\}-\mathrm{p}^{2} \rho \mathrm{I}_{1}(\mathrm{p} \rho)\left[\mathrm{pI} \mathrm{I}_{1}(\mathrm{p})+\mathrm{mI}_{0}(\mathrm{p})\right]\right\} \mathrm{dp} \\
& +\frac{4 m}{\pi} \sum_{i} \frac{1}{\left(m^{2}+\xi_{i}^{2}\right) J_{0}\left(\xi_{i}\right)}\left\{\rho^{-1} \xi_{i} J_{1}\left(\rho \xi_{i}\right) D_{i}(\zeta, \tau)\right. \\
& \left.+J_{0}\left(\rho \xi_{i}\right)\left[F_{i}(\zeta, \tau)-\xi_{i}^{2} D_{i}(\zeta, \tau)\right]\right\} \text {. }
\end{aligned}
$$

\footnotetext{
${ }^{T}$ The explicit expressions for the displacement components have not been included; however, they may be readily computed from Eqs. 46 and 47.
} 


$$
\begin{aligned}
& \hat{\sigma}_{\theta \theta}(\rho, \zeta, \tau)=\frac{2}{\pi} \int_{0}^{\infty} \frac{\sin \mathrm{p} \beta \cos \mathrm{p} \zeta}{\mathrm{p}^{3} \Delta(\mathrm{p})\left[\mathrm{pI} \mathrm{I}_{1}(\mathrm{p})+\mathrm{mI}_{0}(\mathrm{p})\right]}\left\{\mathrm { I } _ { 0 } ( \mathrm { p } \rho ) \left[\left\{\mathrm{m}(1-\nu)+\mathrm{p}^{2}[(1-2 \nu)+\mathrm{m}(1-\nu)]\right\} \mathrm{I}_{1}^{2}(\mathrm{p})\right.\right. \\
& \left.+\mathrm{m}(1-2 \nu) \mathrm{pI}_{0}(\mathrm{p}) \mathrm{I}_{1}(\mathrm{p})-\mathrm{m}(1-\nu) \mathrm{p}^{2} \mathrm{I}_{0}^{2}(\mathrm{p})\right]-\mathrm{p}^{-1} \mathrm{I}_{1}(\mathrm{p} \rho)\left\{\mathrm{m} \nu \mathrm{pI}_{0}^{2}(\mathrm{p})\right. \\
& \left.\left.+\left[\mathrm{m}(1-\nu)+\mathrm{p}^{2}\right] \mathrm{I}_{0}(\mathrm{p}) \mathrm{I}_{1}(\mathrm{p})+(1-\nu)(2+\mathrm{m}) \mathrm{pI}_{1}^{2}(\mathrm{p})\right\}-\Delta(\mathrm{p})\left[\mathrm{pI} \mathrm{I}_{1}(\mathrm{p})+\mathrm{mI}_{0}(\mathrm{p})\right]\right\} \mathrm{dp} \\
& +\frac{4 \mathrm{~m}}{\pi} \int_{0}^{\infty} \frac{\sin \mathrm{p} \beta \cos \mathrm{p} \zeta}{\Delta(\mathrm{p})} \mathrm{C}(\mathrm{p}, \tau)\left\{-(1-2 \nu) \mathrm{pI}_{0}(\mathrm{p} \rho)\left[\mathrm{pI}_{1}(\mathrm{p})+\mathrm{mI}_{0}(\mathrm{p})\right]\right. \\
& \left.+(p \rho)^{-1} I_{1}(p \rho)\left\{p I_{0}(p)\left[p^{2}+2 m(1-\nu)\right]+I_{1}(p)\left\{p^{2}[m+2(1-\nu)]+2(1-\nu)\right]\right\}\right\} d p \\
& -\frac{4 m}{\pi} \sum_{1} \frac{1}{\left(m^{2}+\xi_{1}^{2}\right) J_{0}\left(\xi_{1}\right)}\left[p^{-1} \xi_{1} J_{1}\left(\rho \xi_{1}\right) D_{1}(\zeta, \tau)-J_{0}\left(\rho \xi_{1}\right) F_{1}(\zeta, \tau)\right] \\
& \hat{\sigma}_{\mathrm{zZ}}(\rho, \zeta, \tau)=\frac{2}{\pi} \int_{0}^{\infty} \frac{\sin \mathrm{p} \beta \cos \mathrm{p} \zeta}{\mathrm{p}^{3} \Delta(\mathrm{p})\left[\mathrm{pI} \mathrm{I}_{1}(\mathrm{p})+\mathrm{mI}_{0}(\mathrm{p})\right]}\left\{\left[\mathrm{m}(1-\nu)-\mathrm{p}^{2}\right] \mathrm{I}_{1}(\mathrm{p})-\mathrm{mpI}_{0}(\mathrm{p})\right\}\left\{\mathrm { I } _ { 0 } ( \mathrm { p } \rho ) \left[2 \mathrm{I}_{2}(\mathrm{p})\right.\right. \\
& \left.\left.-p I_{0}(p)\right]+p \rho I_{1}(p \rho) I_{1}(p)\right\} d p+\frac{4 m}{\pi} \int_{0}^{\infty} \frac{\sin p \beta \cos p \zeta}{\Delta(p)} C(p, \tau)\left\{I _ { 0 } ( p \rho ) \left\{p\left(2 m-p^{2}\right) I_{0}(p)\right.\right. \\
& \left.\left.-\left\{2 m(1-\nu)+p^{2}(m-2)\right] I_{1}(p)\right\}+p^{2} \rho I_{1}(p \rho)\left[p I_{1}(p)+m I_{0}(p)\right]\right\} d p \\
& +\frac{4 m}{\pi} \sum_{1} \frac{\xi_{1}^{2} J_{0}\left(\rho \xi_{1}\right)}{\left(m^{2}+\xi_{1}^{2}\right) J_{0}\left(\xi_{1}\right)} D_{1}(\zeta, \tau)
\end{aligned}
$$

and

$$
\begin{aligned}
\hat{\sigma}_{\mathrm{rz}}(\rho, \zeta, \tau)= & \frac{2}{\pi} \int_{0}^{\infty} \frac{\sin \mathrm{p} \beta \sin \mathrm{p} \zeta}{\mathrm{p}^{2} \Delta(\mathrm{p})\left[\mathrm{pI} \mathrm{I}_{1}(\mathrm{p})+\mathrm{mI} \mathrm{I}_{0}(\mathrm{p})\right]}\left\{\left[\mathrm{p}^{2}-\mathrm{m}(\mathrm{l}-\nu)\right] \mathrm{I}_{1}(\mathrm{p})+\mathrm{mpI} \mathrm{I}_{0}(\mathrm{p})\right\} \\
& {\left[\mathrm{I}_{0}(\mathrm{p}) \mathrm{I}_{1}(\mathrm{p} \rho)-\rho \mathrm{I}_{0}(\mathrm{p} \rho) \mathrm{I}_{1}(\mathrm{p})\right] \mathrm{d} \mathrm{p} } \\
& +\frac{4 \mathrm{~m}}{\pi} \int_{0}^{\infty} \frac{\sin \mathrm{p} \beta \cos \mathrm{p} \zeta}{\Delta(\mathrm{p})} \mathrm{C}(\mathrm{p}, \tau)\left\{\mathrm{p}^{2} \rho \mathrm{I}_{0}(\mathrm{p} \rho)\left[\mathrm{pI} \mathrm{I}_{1}(\mathrm{p})+\mathrm{mI}_{0}(\mathrm{p})\right]\right. \\
& \left.-\mathrm{I}_{1}(\mathrm{p} \rho)\left[\mathrm{p}^{3} \mathrm{I}_{0}(\mathrm{p})+\mathrm{mI}_{1}(\mathrm{p})\left[2(1-\nu)+\mathrm{p}^{2}\right]\right]\right\} \mathrm{dp} \\
& +\frac{4 \mathrm{~m}}{\pi} \sum_{1} \frac{\xi_{1} \mathrm{~J}_{1}\left(\xi_{1} \rho\right)}{\left(\mathrm{m}^{2}+\xi_{1}^{2}\right) J_{0}\left(\xi_{1}\right)} \mathrm{E}_{1}(\zeta, \tau) .
\end{aligned}
$$

In the above equations, $C(p, \tau)$ is given in Eq. $43, D_{i}(\zeta, \tau)$ in Eq. 50 , $\Delta(p)$ after Eq. $45, F_{i}(\zeta, \tau)$ in Eq. 30 , and

$$
\begin{aligned}
E_{1}(\zeta, \tau)= & \frac{\pi}{16 \xi_{1}^{3}}\left\{\left(1-2 \mu_{1}^{2}+2 \mu_{1} \gamma_{2}\right) \exp \left(-2 \mu_{1} \gamma_{2}\right) \operatorname{erfc}\left(\mu_{1}-\gamma_{2}\right)+\left(1-2 \mu_{1}^{2}-2 \mu_{1} \gamma_{2}\right) \exp \left(2 \mu_{1} \gamma_{2}\right) \operatorname{erfc}\left(\mu_{1}+\gamma_{2}\right)\right. \\
& -\left(1-2 \mu_{1}^{2}+2 \mu_{1} \gamma_{1}\right) \exp \left(-2 \mu_{1} \gamma_{1}\right) \operatorname{erfc}\left(\mu_{1}-\gamma_{1}\right)-\left(1-2 \mu_{1}^{2}-2 \mu_{1} \gamma_{1}\right) \exp \left(2 \mu_{1} \gamma_{1}\right) \operatorname{erfc}\left(\mu_{1}+\gamma_{1}\right) \\
& \left.+\frac{4 \mu_{1}}{\sqrt{\pi}} \exp \left(\mu_{1}^{2}\right)\left[\exp \left(-\gamma_{2}^{2}\right)-\exp \left(-\gamma_{1}^{2}\right)\right]\right\},
\end{aligned}
$$

where the auxiliary variables are as in Eq. 31. 
Verification that the series and integrals contained in the represen-

tation of the stress field (Eqs. 51-54) are uniformly convergent in $0 \leq \rho \leq 1$, $-\infty<\zeta<\infty$, for all $\tau>0$ is straightforward. Furthermore, termwise differentiation and differentiation under the integral sign as needed to check satisfaction of stress equations of equilibrium are easily justified, and verification of the boundary conditions (Eq. 13) is immediate. It may also be shown that as $\beta \rightarrow \infty$ and $\zeta \rightarrow 0$, the above solution approaches the corresponding plane strain solution. However, this is a somewhat tedious process involving, for example, the expansion of various integrands into power series valid for small values of the variable of integration.

\section{RESULTS AND DISCUSSION}

The numerical work associated with evaluation of the temperature field (Eq. 26) and the stress field (Eqs. 51-54) was performed by a single FORTRAN program run on the IBM SYSTEM 360/75. Beyond the elementary functions, the only needed subroutines were those used to calculate the Bessel functions $J_{0}, J_{1}, I_{0}$, and $I_{1}$, and the complementary error function, plus a root finder to evaluate the $\xi_{i}$ defined by Eq. 22, and an integration routine. The various function routines were standard programs. The integration subroutine was specially written after examination of the stressfield integrands indicated that a modified Simpson's rule with a variable upper integration limit and variable step size would provide sufficient accuracy, there being no need to evaluate the asymptotic "tails" of the integrals. The subroutine to compute the $\xi_{i}$ values was bypassed in most computations in favor of reading in a previously computed set of roots or those obtained from tabulations such as those contained in Ref. 13. The Simpson's-rule subroutine computed the integrals over an increasing number of periods of the integrand, comparing each succeeding value of the integral with the previous until these differed by less than some assigned value $\left(10^{-6}\right.$ in most of the computations). All function subroutines were accurate to at least $7 \mathrm{D}$, and in most cases it was found sufficient to employ only the first six roots $\xi_{i}$ to achieve $7 D$ accuracy in summations such as that defining $\mathrm{C}(\mathrm{p}, \tau)$.

The methods outlined were of sufficient accuracy that, for example, the boundary condition $\hat{\sigma}_{\mathrm{rr}}(1, \zeta, \tau)=0$ was met to $6 \mathrm{D}$ for all $\zeta, \tau$ in the ranges computed. The temperature field and the resulting stresses were evaluated for four combinations of the length of the heat-generating segment, $\beta$, and the Biot number, $m$. The Biot number was taken as either $m=0.1$ or $\mathrm{m}=10.0$, corresponding in a rough sense, respectively, to a poorly cooled cylinder, say gas-cooled, or to a much more efficient coolant, say water. For each value of $\mathrm{m}$, the heat-generating length was either a "small" value, $\beta=0.5$, or a "large" value, $\beta=4.0$. The small value could model the effect of local hot region caused by uneven fuel loading. The large value closely approximates near $\zeta=\beta$ the stress field caused by 
a heat-generation rate in the form of a Heaviside function (the field near $\zeta=\beta$ being insensitive to the jump at $\zeta=-\beta$, particularly for large $\mathrm{m}$ ). This heat-generation rate models the effect of a strong axial gradient in the thermal-neutron flux caused by, say, a partially inserted bank of strong control rods.

In each of the four combinations of the parameters $m$ and $\beta$, the temperature and stresses were computed at $\rho=0,0.5$, and 1 and, for each value of $\rho$, at times $\tau=0.01,0.04,0.1,0.2,0.5,1.0$, and 5.0 plus the steady state, $\tau=\infty$. Axial computations for each $\rho$ and $\tau$ were made at increments $\Delta \zeta=0.1$ for $0 \leq \zeta \leq 2$ in the case $\beta=0.5$ and at increments $\Delta \zeta=0.5$ for $0 \leq \zeta \leq 8$ plus $\Delta \zeta=0.2$ for $3 \leq \zeta \leq 5$ in the case $\beta=4.0$. This amounted to evaluating Eqs. 26 and $51-54$ for almost 8,000 combinations of $\mathrm{m}, \beta, \rho, \zeta$, and $\tau$ and required approximately $120 \mathrm{~min}$ on the SYSTEM $360 / 75$.

The numerical results presented consist of four groups of four graphs, one group of four for each pair of parameter values $m$ and $\beta$. Each group gives the axial variation of temperature, axial stress, and circumferential stress at the surface and centerline and the shear stress at the radial midpoint, $\rho=0.5$. The radial stress component is not explicitly shown. However, its general features may be determined from the graphs since at the centerline it is identical to $\hat{\sigma}_{\theta \theta}$ and it vanishes at the cylinder surface. Appropriate steady-state plane-strain values at $\rho=0,1$ have also been included on each graph as convenient points of reference for comparison of corresponding results with differing parameter values $m$ and $\beta$.

Figures 1-4 refer to the well-cooled cylinder generating heat within a large axial segment $(\mathrm{m}=10, \beta=4)$. With the exception of a small region near $\zeta=\beta$, the heat-generating part of the cylinder is in a state of plane strain, the shear stress is quite localized and has appreciable magnitude only near $\zeta=\beta$, and transient stress levels in most regions never exceed steady-state values. In Figs. 5-8, the heat-generating length is as in the first case $(\beta=4)$, but the surface cooling is poor $(m=0.1)$. Hence the temperatures are higher, almost flat radially, and decay more slowly in the axial direction than the $m=10$ case. Also, the time needed to closely approximate steady-state conditions is larger by an order of magnitude, the stress field is approximately plane over a much smaller region and decays slower axially, and the steady-state plane solution is a poorer approximation to the true steady-state values. It is still true, however, that within the heat-generating region, the transient stress levels do not exceed the steady-state values.

Figures 9-16 refer to the case $\beta=0.5$, a "small" heat-generating segment. With the exception of the radial and circumferential components of stress near the cylinder centerline, the stress levels for this case are generally lower than the $\beta=4$ cases and there is noappreciable region where a state of plane strain exists. Again the steady-state values provide an upper bound to the transient stress levels over most regions of the cylinder. 


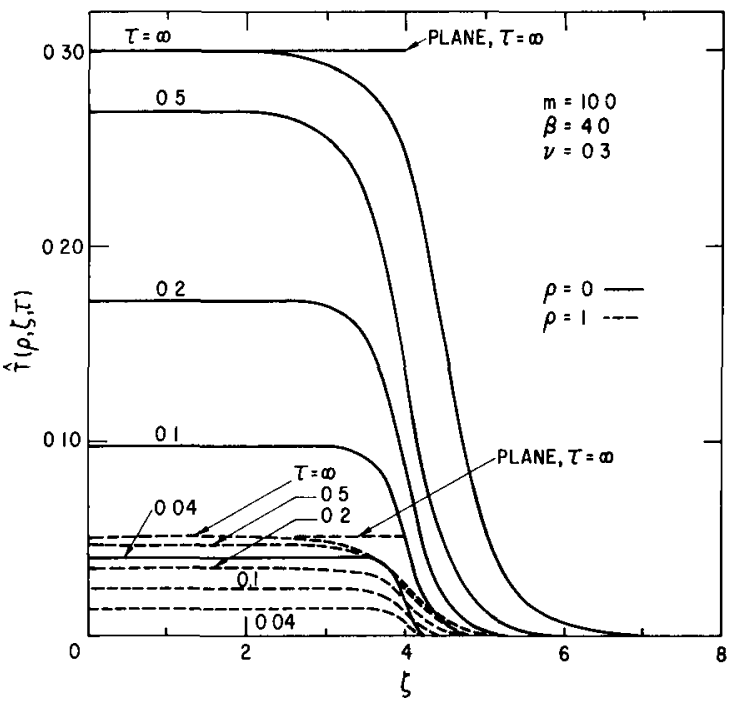

Fig. 1. Temperature at $\rho=0$ and $\rho=1$ as a Function of $\zeta$ for Various Values of $\tau ; m=10, \beta=4.0$

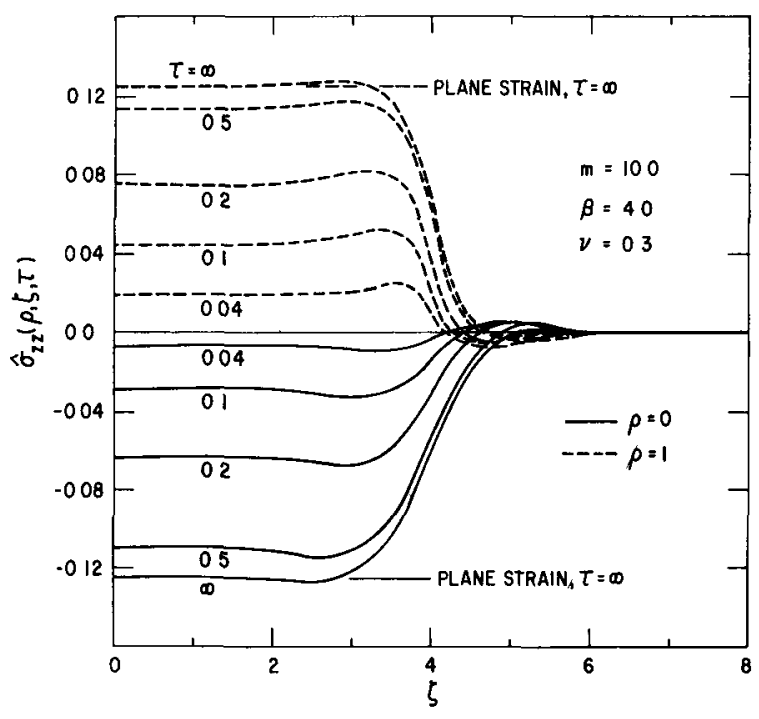

Fig. 3. Axial Stress at $\rho=0$ and $\rho=1$ as a Function of $\zeta$ for Various Values of $\tau ; m=10$, $\beta=4.0$

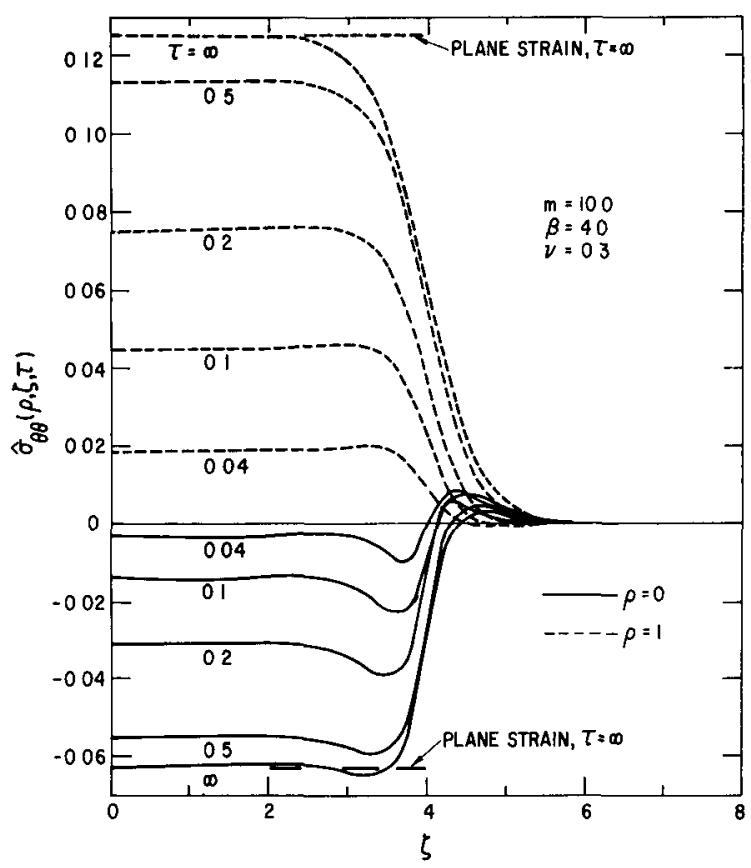

Fig. 2. Circumferential Stress at $\rho=0$ and $\rho=1$ as a Function of $\zeta$ for Various Values of $\tau ; m=10, \beta=4.0$

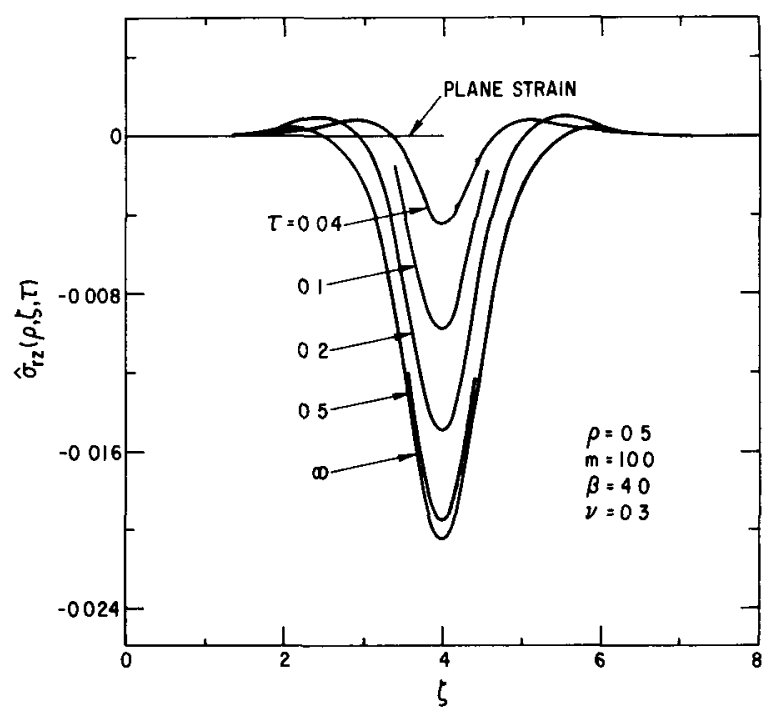

Fig. 4. Shear Stress at $\rho=0.5$ as a Function of $\zeta$ for Various Values of $\tau ; m=10, B=4.0$ 


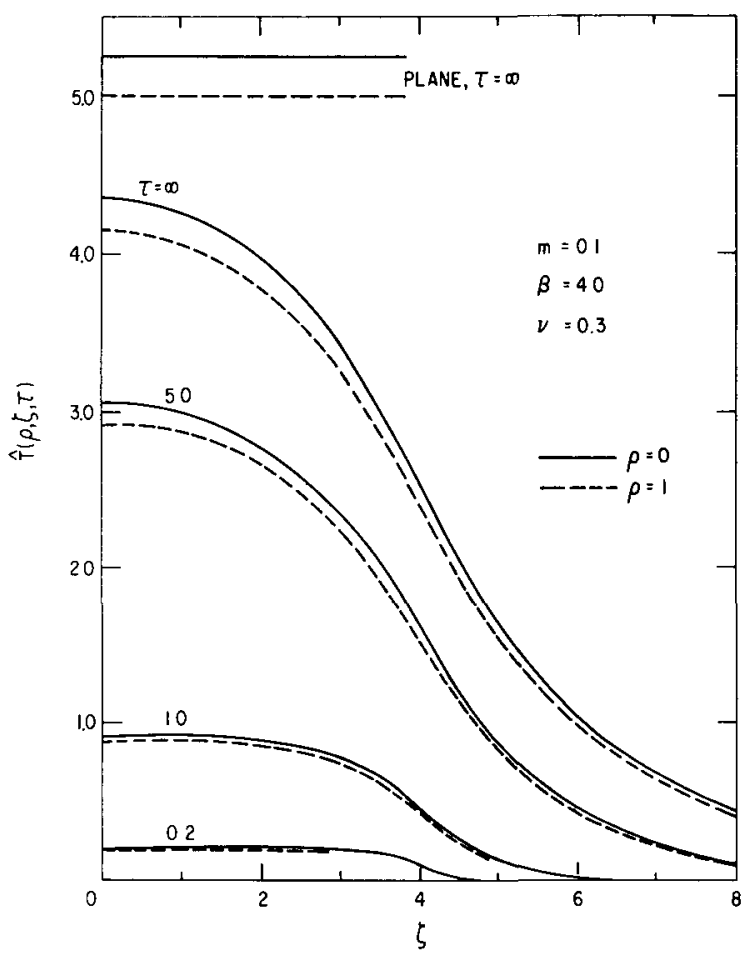

Fig. 5. Temperature at $\rho=0$ and $\rho=1$ as a Function of $\zeta$ for Various Values of $\tau$; $\mathrm{m}=0.1, \beta=4.0$

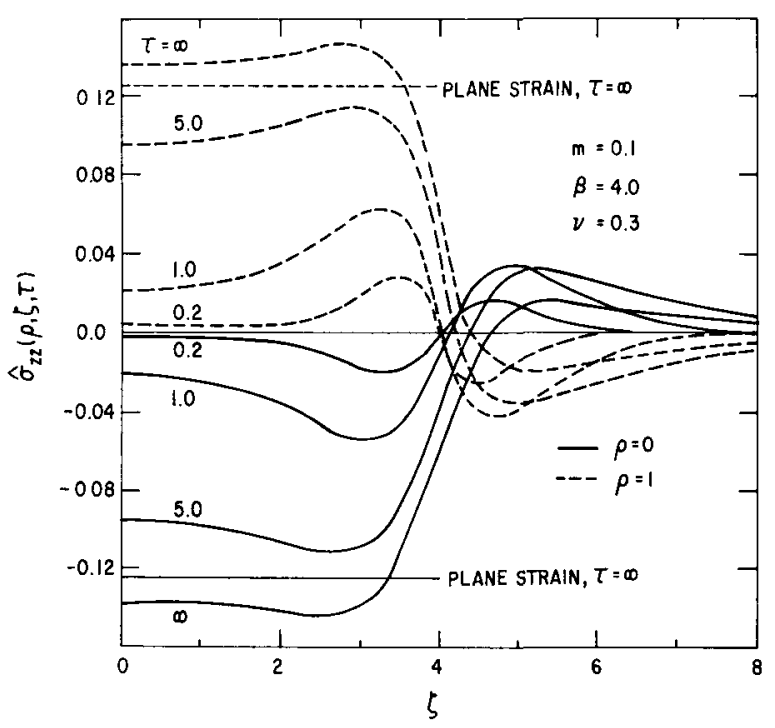

Fig. 7. Axial Stress at $\rho=0$ and $\rho=1$ as a Func tion of $\zeta$ for Various Values of $\tau ; m=0.1$, $\beta=4.0$

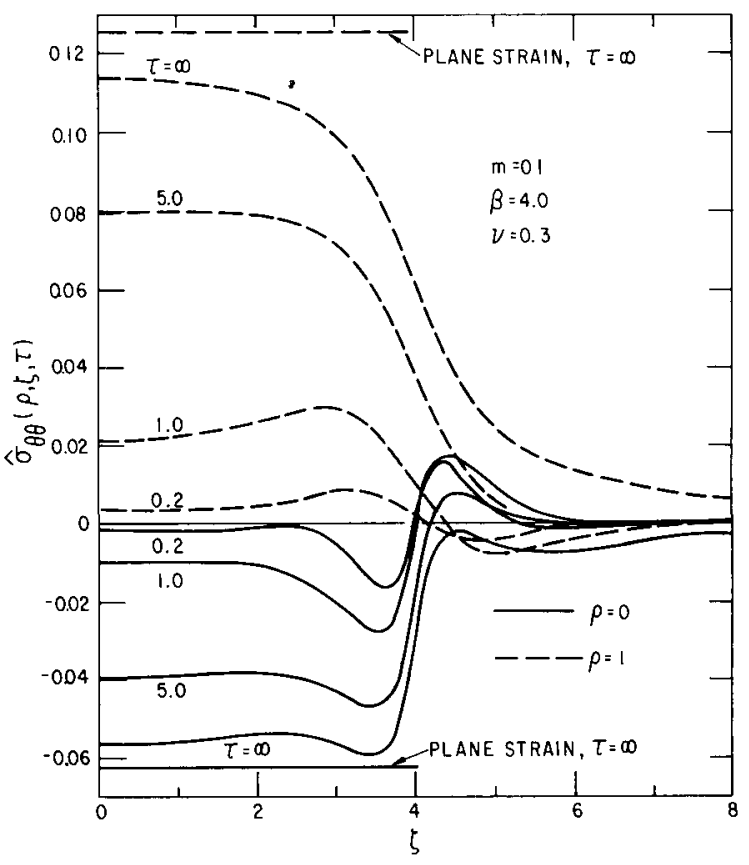

Fig. 6. Circumferential Stress at $\rho=0$ and $\rho=1$ as a Function of $\zeta$ for Various Values of $\tau$; $\mathrm{m}=0.1, \beta=4.0$

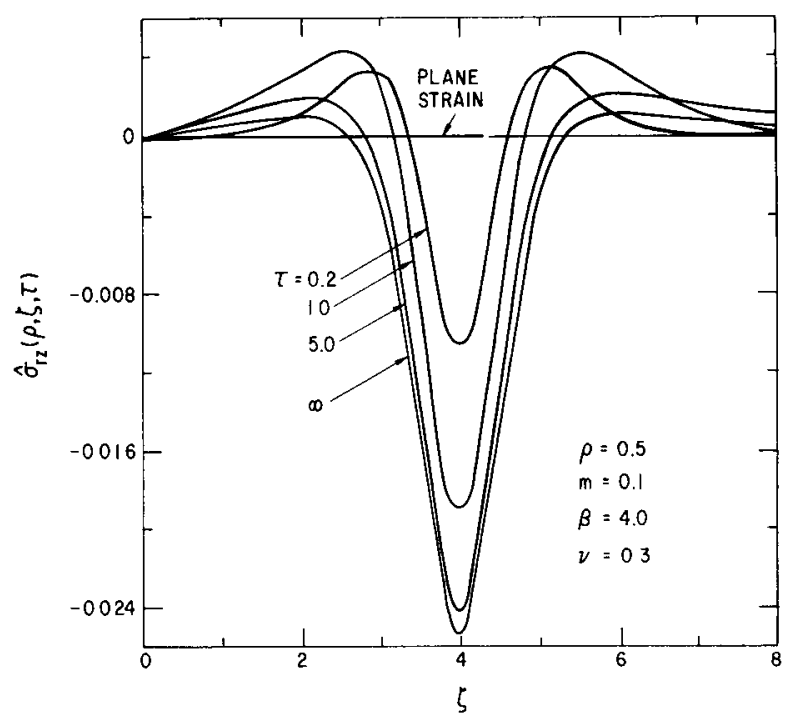

Fig. 8. Shear Stress at $\rho=0.5$ as a Function of $\zeta$ for Various Values of $\tau ; m=0.1, \beta=4.0$ 


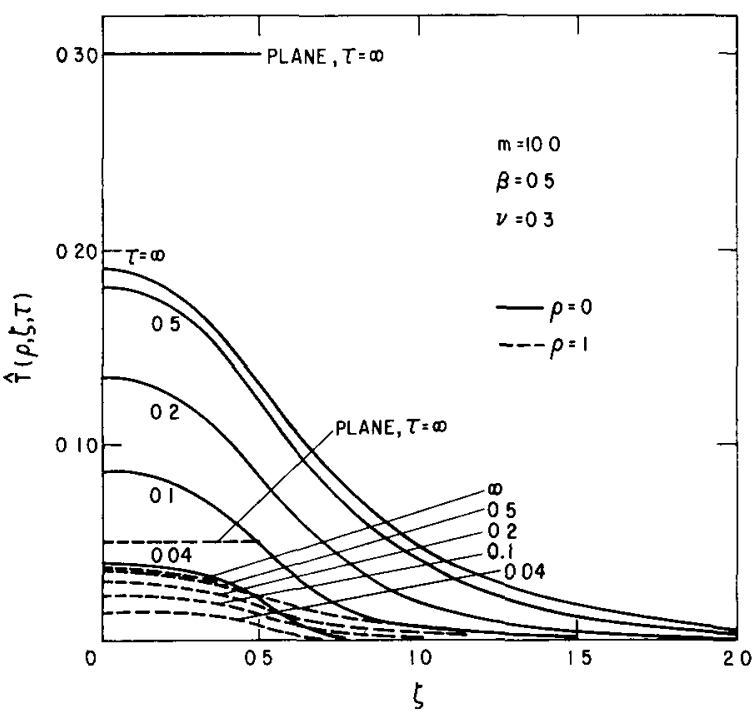

Fig. 9. Temperature at $\rho=0$ and $\rho=1$ as a Function of $\zeta$ for Various Values of $\tau$; $\mathrm{m}=10.0, \beta=0.5$

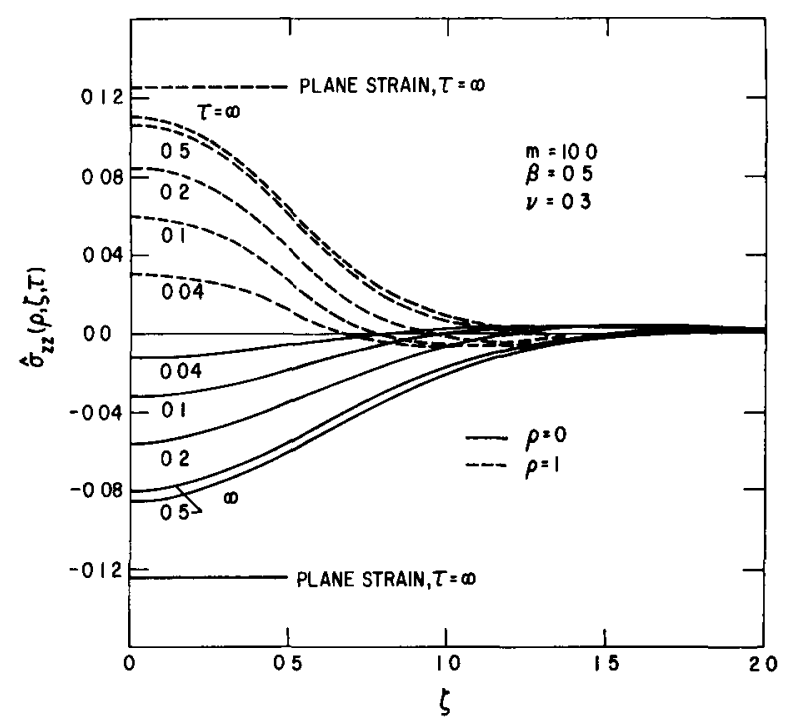

Fig. 11. Axial Stress at $\rho=0$ and $\rho=1$ as a Function of $\zeta$ for Various Values of $\tau_{i} m=10.1$, $\beta=0.5$

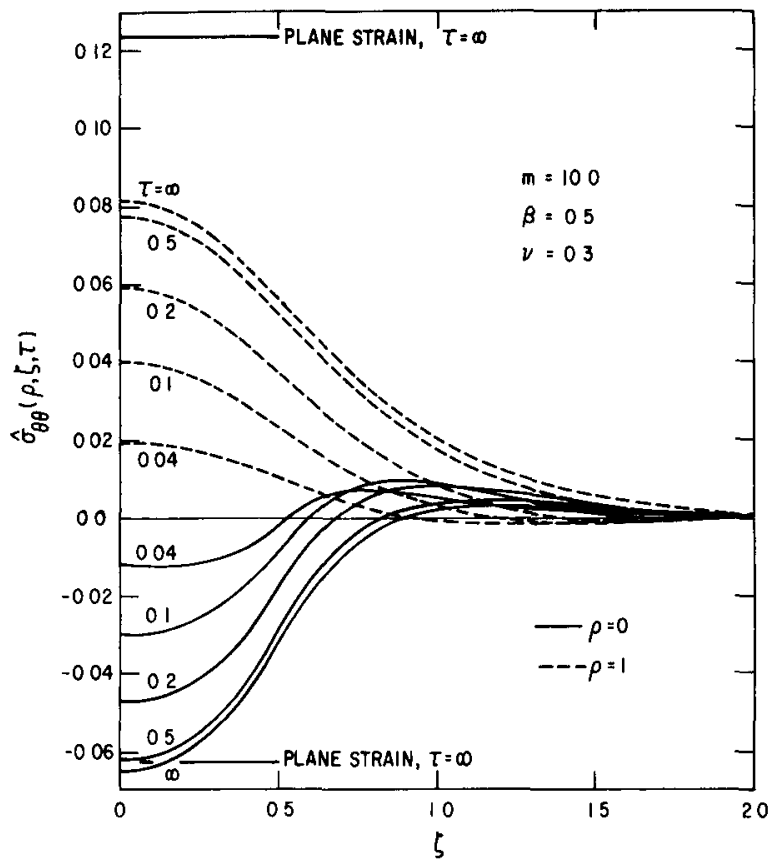

Fig. 10. Circumferential Stress at $\rho=0$ and $\rho=1$ as a Function of $\zeta$ for Various Values of $\tau$; $\mathrm{m}=10.0, \beta=0.5$

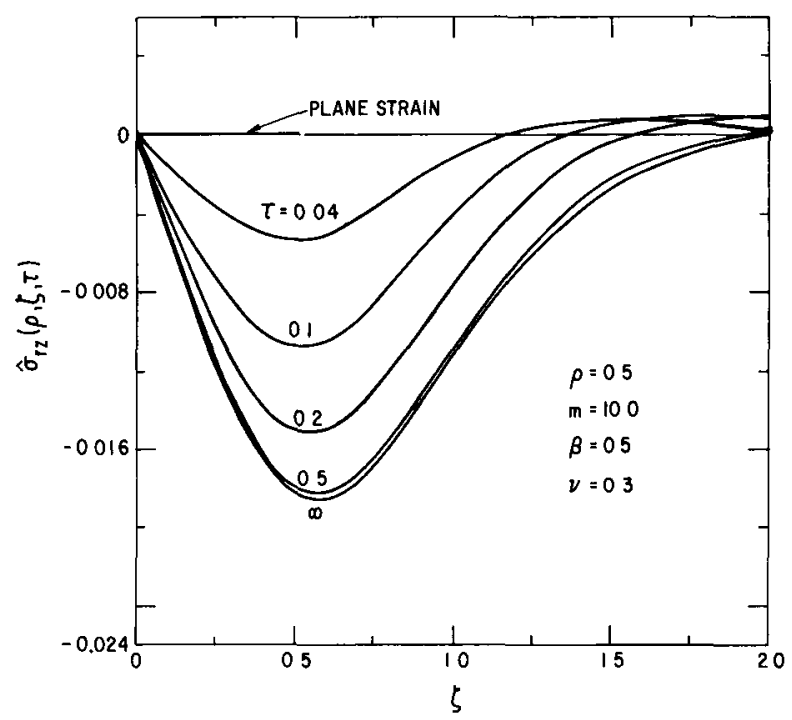

Fig. 12. Shear Stress at $\rho=0.5$ as a Function of $\zeta$ for Various Values of $\tau ; m=10.0, \beta=0.5$ 


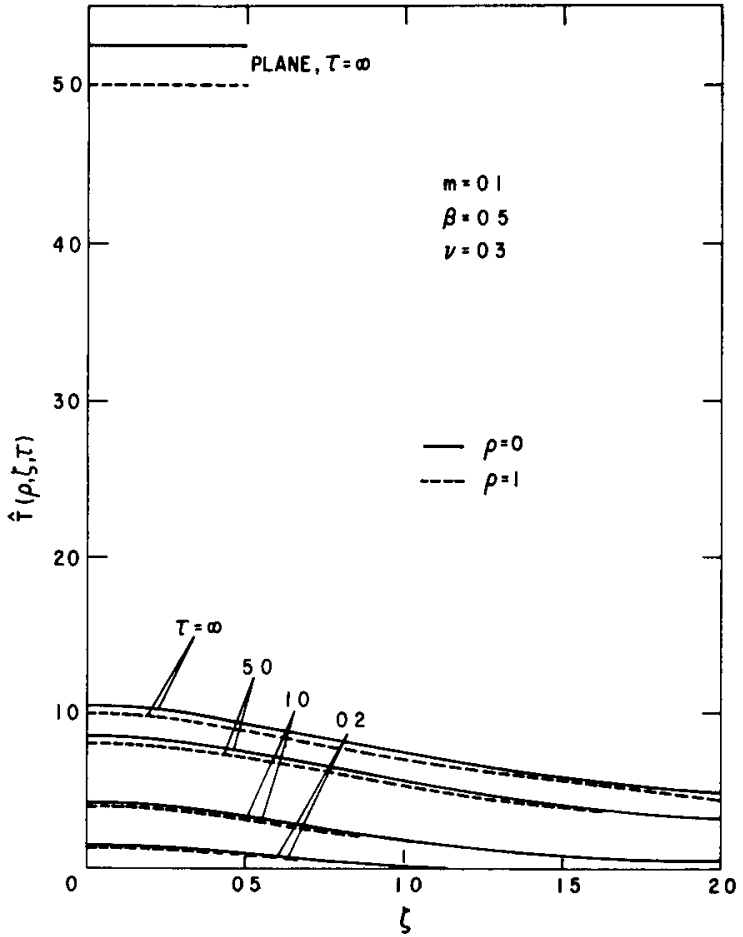

Fig. 13. Temperature at $\rho=0$ and $\rho=1$ as a Function of $\zeta$ for Various Values of $\tau$; $\mathrm{m}=0.1, \beta=0.5$

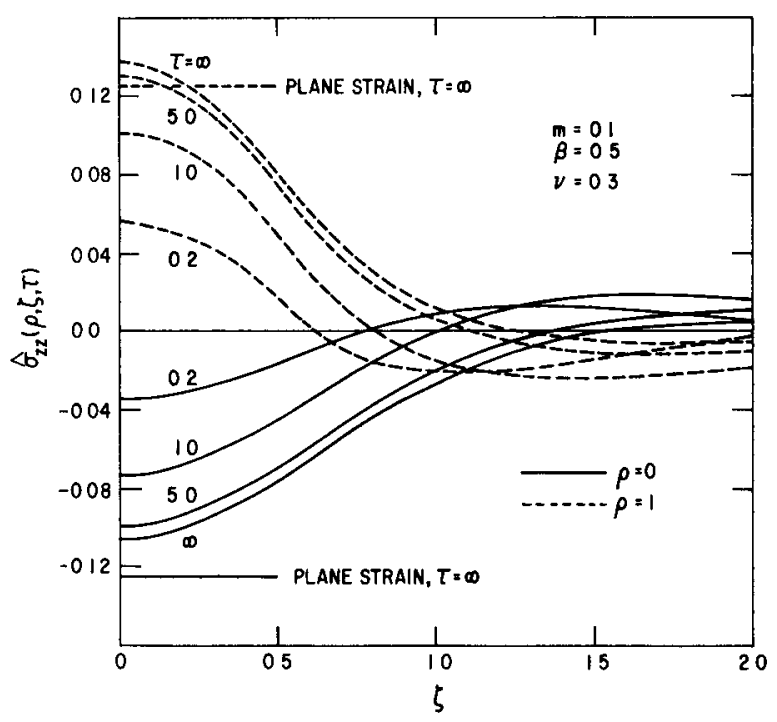

Fig. 15. Axial Stress at $\rho=0$ and $\rho=1$ as a Function of $\zeta$ for Various Values of $\tau ; m=0.1$, $\beta=0.5$

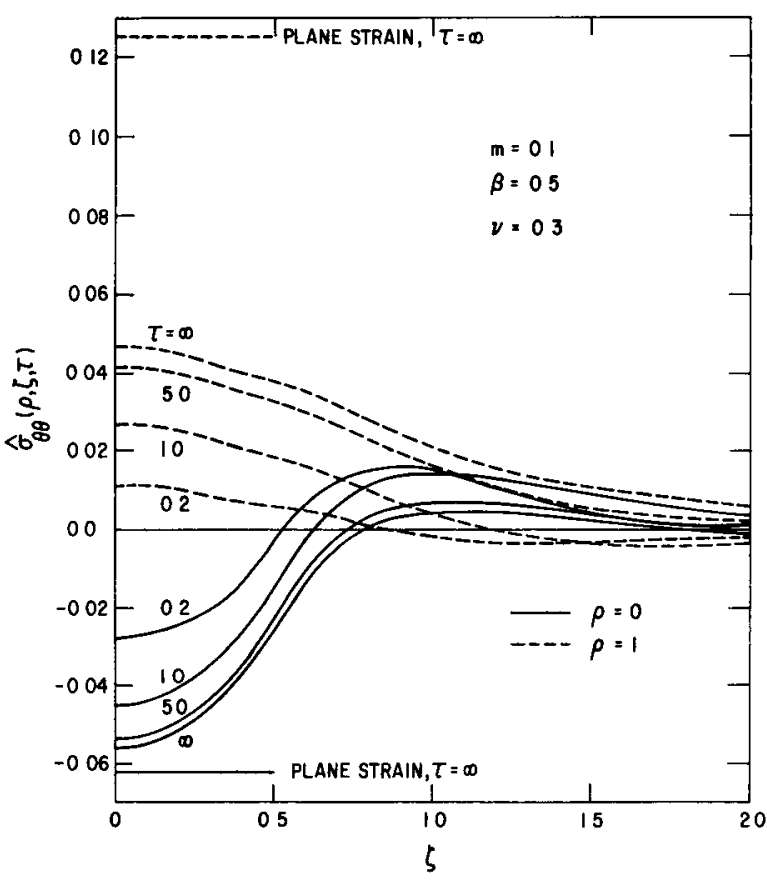

Fig. 14. Circumferential Stress at $\rho=0$ and $\rho=1$ as a Function of $\zeta$ for Various Values of $\tau$; $\mathrm{m}=0.1, \beta=0.5$

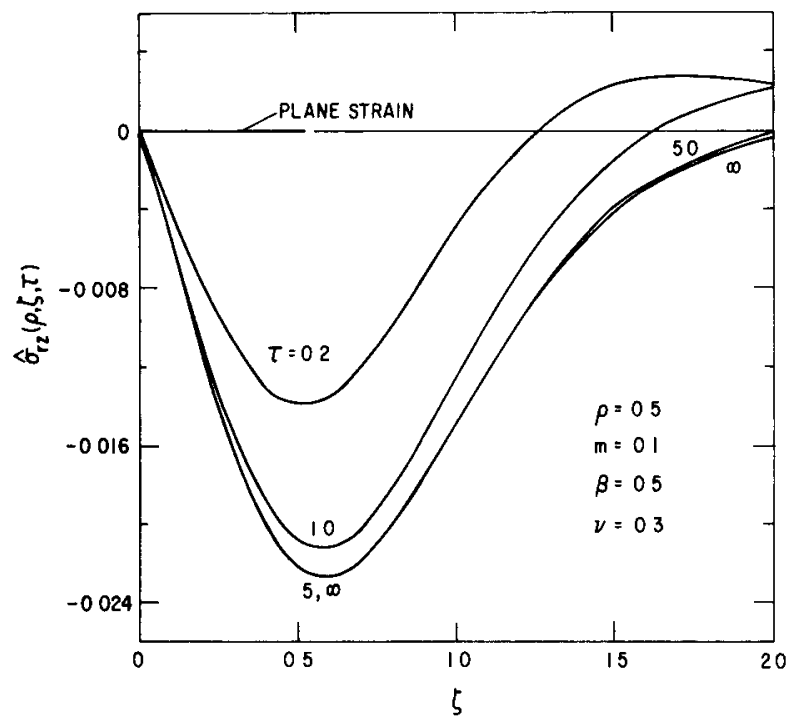

Fig. 16. Shear Stress at $\rho=0.5$ as a Function of $\zeta$ for Varıous Values of $\tau, m=0.1, \beta=0.5$ 


\section{REFERENCES}

1. Zudans, Zenons, Q. C. Yen, and W. H. Steigelmann, ThermaZ Stress Techniques in the Nuclear Industry, American Elsevier, New York (1965).

2. Reactor Handbook, Vol. IV, Engineering, McLain, Stewart, and J. H. Martens, eds., 2nd ed., Interscience, New York (1964).

3. Burgreen, David, Thermoezastic Dynamics of Rods, Thin Shells, and Solid Spheres, Nucl. Sci. Eng. 12 (1962), pp. 203-217.

4. Kolesov, V. F., On the Dynomics of a Spherically Symmetric Pulsed Fast Reactor, Atomn. Energ. 14 (1963), pp. 273-280.

5. Youngdahl, C. K., and Eli Sternberg, Transient Thermal Stresses in a Circular Cylinder, J. Appl. Mech. 28 (1961), pp. 25-34.

6. Hoyle, R. D., Transient Temperature Stresses in Axially Symmetrical Systems with Special Application to a Solid Rotor of a Steam Turbine, Proc. Inst. Mech. Engrs. 169 (1955), pp. 553-562.

7. Nowacki, W., Thermoelasticity, Addison-Wesley, Reading, Mass. (1962).

8. Singh, A., Axisymmetrical Thermal Stresses in Transversely Isotropic Bodies, Arch. Mech. Stoj. 12 (1960), pp. 287-304.

9. Love, A. E. H., A Treatise on the Mathematical Theory of Elasticity, 4 th ed., Dover, New York (1944).

10. Sneddon, Ian N., Fourier Transforms, McGraw-Hil1, New York (1951).

11. Gradshteyn, Q. S., and I. M. Ryzhik, Table of Integrals, Series, and Products, Academic Press, New York (1965).

12. Staff of the Bateman Manuscript Project, Tables of Integral Transforms, Vo1. 1, McGraw-Hi11, New York (1954).

13. Carlaw, H. So, and J. C. Jaeger, Conduction of Heat in Solids, 2nd ed., Clarendon Press, Oxford (1959). 